\title{
Les Leuconostocs \\ Propriétés : leur rôle en technologie laitière
}

\author{
J.J. DEVOYOD, Françoise POULLAIN \\ INRA, Laboratoire de Microbiologie laitière, 78350 Jouy-en-Josas, France
}

\section{Résumé}

Les principaux caractères biochimiques des Leuconostocs, bactéries lactiques hétérofermentaires sont examinés. Après un rappel des différentes classifications taxonomiques successives, l'étude bibliographique de l'écologie des Leuconostocs est faite en tenant compte plus particulièrement des produits laitiers, du matériel et de la vaisselle laitière.

Parmi les caractères biochimiques, les plus importants sont : la fermentation des sucres, la fermentation du citrate, la production de dextrane et la production de substances inhibitrices.

Dans une troisième partie, il est traité de l'utilisation réelle et potentielle des Leuconostocs comme levains d'arôme, pour améliorer la structure des fromages et pour éliminer certains défauts de goût.

Aux connaissances relevées dans la littérature, ont été ajoutés des résultats personnels obtenus sur 210 souches de Leuconostocs isolés principalement de fromages traditionnels fabriqués à partir de lait cru.

Mots clés : Leuconostocs - Taxonomie - Ecologie - Métabolisme - Produits laitiers Fromages - Arômes - Affinage.

\section{Summary}

The Leuconostocs. Characteristics - Their role in dairy technology

The main biochemical characteristics of the heterofermentative lactic acid bacteria, Leuconostocs are reviewed. The principal successive taxonomical classifications are discussed and the ecology of these microorganisms is cited mainly according to the dairy environment (dairy products, dairy machinery and so on...).

The more important biochemical characteristics in Leuconostocs species are sugar fermentation, citrate dissimilation, dextran formation and inhibitory substances production.

The real and potential uses of Leuconostocs as aroma starters, to improve cheese structure or to eliminate some flavour defects are discussed. 
In addition to the bibliographic review, personal data concerning 210 strains of Leuconostocs isolated from traditional raw-milk cheeses are given.

Key-Words : Leuconostocs, Taxonomy, Ecology, Metabolism, Dairy products, Cheese, Flavour, Ripening.

\section{Introduction}

Les Leuconostocs sont loin de faire l'unanimité dans le monde de la technologie laitière; si certains utilisateurs les emploient comme levain pour améliorer la qualité de leurs produits (beurre, pâtes fraîches, fromages à pâte persillée), d'autres les redoutent pour les accidents de fabrication dont on les rend, à tort ou à raison, responsables.

Du point de vue taxonomique, leur classification n'a guère été satisfaisante jusqu'à ces dernières années et les critères de différenciation entre les espèces et sous-espèces ne sont pas toujours aisés à mettre en œuvre. Les Leuconostocs sont capables de se développer dans de nombreux produits naturels simples ou élaborés, produits d'origine végétale ou animale, sans que l'on sache vraiment s'il s'agit des mêmes biotypes ou non. La confusion est fréquemment faite entre ces microorganismes et les lactobacilles hétérofermentaires mésophiles. Toutes ces raisons nous ont incités à essayer de faire le point des connaissances sur les propriétés des Leuconostocs. A ces connaissances relevées dans la littérature, nous avons ajouté des résultats personnels obtenus lors d'études sur la flore de fromages traditionnels fabriqués à partir de lait cru.

\section{Le genre Leuconostoc}

\section{A. Historique}

Le genre Leuconostoc a été défini par Van Thieghem en 1878. Le terme Leuconostoc vient du mot Nostoc qui est une algue bleue mucilagineuse et de leuco qui veut dire blanc. Les Leuconostocs sont apparus à l'origine (rappelons qu'à cette époque, l'examen microscopique, c'est-à-dire la morphologie, était un critère prédominant de l'identification), sous forme de chaînes, d'aspect mucilagineux, non pigmentés. Les premières souches ont été isolées à partir d'accidents apparus dans des sucreries. Or les Leuconostocs responsables de ces accidents produisent des dextranes et en milieu saccharosé, les chaînes de cocci sont entourées d'une gaine bien distincte à l'examen microscopique : gaine qui rappelle celle des Nostocs.

Ce n'est qu'en 1912 que BeIJERINCK isola du beurre et d'autres produits laitiers des microorganismes identiques aux Leuconostocs antérieurement décrits, ces microorganismes produisaient de la gomme à partir du saccharose : il les appela Lactococcus dextranicus.

En 1919, Orla-Jensen, dans son étude sur les bactéries lactiques sépara le genre Betacoccus du genre Streptococcus. Il choisit de donner le nom de 
Betacoccus à ces bactéries produisant de l'acide lactique $\mathrm{D}(-)$ parce que ces bactéries se trouvaient sur les betteraves (Beta communis) et autres produits végétaux. Les résultats d'ORLA-JENSEN montraient pour la première fois qu'il existait une relation possible entre les Leuconostocs produisant des dextranes (Betacoccus) et certains streptocoques producteurs d'acide lactique, streptocoques trouvés dans les produits laitiers et les végétaux fermentés. OrLA-JENSEN divisait le genre Betacoccus en deux espèces $B$. arabinosaceus et $B$. bovis d'après leur capacité de fermenter l'arabinose.

En 1920, Намmer, étudiant les streptocoques des levains, isola deux espèces qu'il dénomma Streptococcus citrovorus et $S$. paracitrovorus, reconnues comme responsables de l'arôme du beurre. Ces microorganismes furent, quelques années plus tard, assimilés au genre Betacoccus et $S$. citrovorus devint B. cremoris.

En ce qui concerne le caractère hétérofermentaire des Leuconostocs, c'està-dire leur capacité de produire du $\mathrm{CO}_{2}$ à partir du glucose, mis en évidence en 1918 par Evans, il fut confirmé par Hucker en 1928.

Les Leuconostocs ont pris peu à peu un intérêt économique potentiel et des tentatives de classification sont apparues dès les années 30 .

\section{B. Les principales classifications}

\section{Hucker et Pederson (1931)}

La première classification exhaustive du genre Leuconostoc est celle de Hucker et Pederson de 1931 qui ont étudié 80 souches d'origines très diverses (sirop de sucre, légumes en fermentation, y compris de choucroute, fenouils marinés, haricots verts, betteraves, blettes, produits fermentés à base de tomates ainsi que de lait et de produits laitiers). Ils ont classé le genre Leuconostoc en trois groupes:

- Le groupe I ne fermentant pas le saccharose : Leuconostoc citrovorus.

- Le groupe II fermentant le saccharose et les pentoses: Leuconostoc mesenteroides.

- Le groupe III fermentant le saccharose mais non les pentoses : Leuconostoc dextranicus.

Les groupes II et III sont des producteurs de dextrane, or bien que Leuconostoc citrovorus ne produise pas de dextranes, les propriétés de production de gomme par des organismes faibles producteurs d'acide isolés de levains montrent, d'après Hucker et Pederson, qu'ils sont identiques aux organismes dextrane-positifs isolés des végétaux et des sirops de sucre.

\section{Abd-el-Malek et Gibson (1948)}

Dans leur travail sur la bactériologie du lait ABD-EL-MaLeK et GibSon ont étudié 40 souches de streptocoques hétérofermentaires isolées du lait. Tous ces microorganismes se développaient (lentement) à $8-12{ }^{\circ} \mathrm{C}$ mais non à $45^{\circ} \mathrm{C}$. Ils 
produisaient de l'acide à partir du glucose. Le xylose, le mannitol et le sorbitol n'étaient pas fermentés. Ils produisaient du $\mathrm{CO}_{2}$ à partir du glucose et du citrate. L'arginine, l'hippurate et l'esculine n'étaient pas hydrolysés. Les cultures sur milieu gélatiné, saccharosé ne mettaient pas en évidence la synthèse de dextranes.

D'après ces auteurs, la majorité des souches de streptocoques hétérofermentaires ont été identifiées comme appartenant à l'espèce Str. kefir. Par contre Str. citrovorus ne fut isolé qu'occasionnellement.

Il semble bien que sous le nom de Str. kefir, Abd-el-Malek et Gibson aient isolé également Leuconostoc mesenteroides (saccharose positif et arabinose positif). La production de dextranes à partir de saccharose dans le genre Leuconostoc est un caractère qui peut prêter à confusion. En effet, si les souches de Leuconostoc isolées de sirop de sucre, de mélasse ou de bagasse sont assez stables de ce point de vue, Pederson et Albury (1955) ont montré que par repiquages successifs, principalement en milieu acide additionné soit de jus de tomate, soit de jus d'orange, beaucoup de souches atypiques redevenaient typiques. C'est ainsi que des souches non productrices de dextranes retrouvaient la possibilité d'en produire et simultanément se trouvaient capables d'utiliser certains sucres qu'elles ne fermentaient pas auparavant. Par contre après plusieurs repiquages dans des milieux à teneur croissante en sel, de nombreuses souches de Leuconostoc perdaient leur capacité de produire des dextranes. La production de dextrane dépend également des températures de croissance (McClesKey et al., 1947).

\section{Garvie (1960)}

Un examen de 78 souches de Leuconostoc a permis à Garvie de diviser le genre Leuconostoc en 3 groupes : L. citrovorum (ou L. cremoris), L. kefir (ou $L$. lactis), $L$. dextranicum et $L$. mesenteroides (3 groupes). Dans leur mise au point sur l'identification des bactéries lactiques SHARPE et al. en 1966 ont repris cette classification. Les Leuconostocs sont des bactéries lactiques hétérofermentaires se présentant sous forme de cocci associés par paires ou en chaînes, n'hydrolysant pas l'arginine, ne se développant pas à $45^{\circ} \mathrm{C}$. Ils produisent à partir du glucose du $\mathrm{CO}_{2}$ et forment tous de l'acide lactique $\mathrm{D}(-)$.

\section{Garvie (1974) dans Bergey's Manual $8^{\mathrm{e}}$ édition}

En 1967 Garvie isole du vin une nouvelle espèce de Leuconostoc qu'elle dénomme $L$. oenos. Cet auteur fut chargé de rédiger le chapitre relatif aux Leuconostocs pour la $8^{\mathrm{e}}$ édition du Bergey's Manual (1974); elle a classé les Leuconostocs en 6 espèces : L. mesenteroides, $L$. dextranicum, $L$. paramesenteroides, $L$. lactis, $L$. cremoris et $L$. oenos selon des critères voisins de ceux utilisés pour la différenciation des lactobacilles (fermentation des sucres, besoins nutritifs, action sur le lait tournesolé, croissance dans différentes conditions, etc.).

$L$. mesenteroides et $L$. dextranicum se trouvent souvent dans les mêmes habitats que le lactobacille hétérofermentaire Lactobacillus brevis. Comme ils se développent tous sur les mêmes milieux sélectifs (Rogosa et al., 1951; 
Mabbitt et Zielinska, 1956, McDonald et al., 1987) il est difficile de les isoler les uns des autres d'autant que morphologiquement ils peuvent se présenter sous la forme de coccobacilles (Perry et Sharpe, 1960).

Toutefois les Leuconostocs à l'inverse de $L b$. brevis fermentent le tréhalose et ne produisent pas d'ammoniaque à partir de l'arginine; de plus ils forment de l'acide lactique $\mathrm{D}(-)$ tandis que $L b$. brevis produit de l'acide lactique racémique.

\section{Données récentes - Tendances actuelles - Garvie (1986) dans Bergey's} Manual of Systematic Bacteriology (Vol. 2)

La séparation du genre Leuconostoc en six espèces distinctes n'était guère satisfaisante. Si L. oenos se distinguait bien des autres espèces de Leuconostoc, la proposition de nouvelles souches types pour les espèces $L$. mesenteroides, $L$. dextranicum et $L$. cremoris (GARVIE, 1979) ne résolut pas le problème et dès $1983, L$. dextranicum et $L$. cremoris étaient reconnus comme étant des sous-espèces de $L$. mesenteroides (GARVIE, 1983). La classification qui prévaut actuellement (GARviE, 1986) a été établie grâce à l'utilisation, à côté des techniques biologiques classiques, de techniques d'hybridation d'ADN (GARviE, 1976, 1983 ; HonteBeyrie et GASSER, 1977) ou de techniques immunologiques (Hontebeyrie et GasSER, 1975). Les corps cellulaires des Leuconostocs peuvent être sphériques, mais souvent lenticulaires, surtout lorsqu'ils sont cultivés sur milieu gélosé. Ils apparaissent le plus souvent par paires ou en chaînes. Ils sont Gram-positifs, non mobiles, ne produisent pas de spores et sont anaérobies facultatifs. Leur optimum de température se situe entre 20 et $30^{\circ} \mathrm{C}$. Ils sont chemo-organotrophes, nécessitant pour se développer des milieux riches comportant des facteurs de croissance complexes et des acides aminés. Toutes les espèces de Leuconostoc ont besoin, pour se développer de l'ensemble acide nicotinique + thiamine + biotine + acide panthoténique (ou l'un de ses dérivếs). La croissance ne se fait qu'en présence d'un sucre fermentescible et le glucose est fermenté selon une combinaison des voies hexose-phosphate et phosphoketolase. Les produits terminaux sont l'éthanol et l'acide D- $(-)$ lactique. Le malate peut être utilisé et transformé en L-(+)-lactate.

Les Leuconostocs ne possèdent ni catalase, ni cytochromes. Ils ne produisent pas d'HN $\mathrm{H}_{3}$ à partir de l'arginine et le lait est en général ni acidifié, ni coagulé. Ce sont des germes non protéolytiques, ne produisant pas d'indole et ne réduisant pas les nitrates. Ils ne sont pas hémolytiques et non pathogènes pour les végétaux et les animaux (y compris les humains).

Les caractères de différenciation des espèces de Leuconostoc sont donnés dans les tableaux 1 et 2 .

Par analogie phylogénique, StackeBrandt et al. (1983) trouvent que L. mesenteroides, Pediococcus pentosaceus et les espèces de Lactobacillus (L. acidophilus, helveticus, lactis, brevis, plantarum, ruminis, casei, bifermentans, viridescens, fermentum) forment un groupe cohérent ce qui confirme les résultats d'études immunologiques antérieures (LONDON et CHASE, 1976). Tandis qu'Orberg et SANDINE (1984) estiment que les Leuconostocs sont taxonomiquement et écologiquement apparentés aux streptocoques du groupe $\mathrm{N}$. 


\section{TABleau 1}

Caractères principaux de différenciation des espèces du genre Leuconostoc (Garvie, 1986) Differential characteristics of the species of the genus Leuconostoc

\begin{tabular}{|c|c|c|c|c|}
\hline \multirow[b]{2}{*}{ Caractères } & \multicolumn{3}{|c|}{ 1. L. mesenteroides, subsp. } & \multirow{2}{*}{$\begin{array}{l}\text { 2. L. para- } \\
\text { mesente- } \\
\text { roides }\end{array}$} \\
\hline & $\begin{array}{l}1 \text { a. } \\
\text { mesente- } \\
\text { roides }\end{array}$ & $\begin{array}{c}1 \mathrm{~b} . \\
\text { dextra- } \\
\text { nicum }\end{array}$ & $\begin{array}{c}1 \mathrm{c} . \\
\text { cremoris }\end{array}$ & \\
\hline \multicolumn{5}{|l|}{ Production d'acide à partir de : } \\
\hline Arabinose & + & - & - & $\mathrm{d}$ \\
\hline Cellulose & d & $\mathrm{d}$ & - & (d) \\
\hline Fructose & + & + & - & + \\
\hline Saccharose & + & + & - & + \\
\hline Trehalose & + & + & - & + \\
\hline Hydrolyse de l'esculine & d & $\mathrm{d}$ & - & $\mathrm{d}$ \\
\hline Formation de dextrane & + & + & - & - \\
\hline Croissance à $\mathrm{pH} 4,8$ & - & - & - & $\mathrm{d}$ \\
\hline $\begin{array}{l}\text { Croissance en présence de } 10 \% \\
\text { d'éthanol }\end{array}$ & - & - & - & - \\
\hline
\end{tabular}

+ : positif $\quad-:$ négatif $\quad \mathrm{d}$ : réaction lente.

\section{TABleau 2}

Caractères supplémentaires de différenciation des espèces du genre Leuconostoc (Garvie, 1986)

Additional characteristics of the species of the genus Leuconostoc

\begin{tabular}{|c|c|c|c|c|c|c|}
\hline \multirow[b]{2}{*}{ Caractères } & \multicolumn{3}{|c|}{ 1. L. mesenteroides, subsp. } & \multirow{2}{*}{$\begin{array}{l}\text { 2. L. pa- } \\
\text { ramesen- } \\
\text { teroides }\end{array}$} & \multirow[b]{2}{*}{$\begin{array}{l}\text { 3. L. } \\
\text { lactis }\end{array}$} & \multirow[b]{2}{*}{$\begin{array}{l}4 . \\
\text { L. oenos }\end{array}$} \\
\hline & $\begin{array}{l}1 \mathrm{a} . \\
\text { mesente- } \\
\text { roides }\end{array}$ & $\begin{array}{l}1 \text { b. dex- } \\
\text { tranicum }\end{array}$ & $\begin{array}{l}1 \text { c. cre- } \\
\text { moris }\end{array}$ & & & \\
\hline \multicolumn{7}{|l|}{$\begin{array}{l}\text { Production d'acide } \\
\text { à partir de : }\end{array}$} \\
\hline Amygdaline & $\mathrm{d}$ & $\mathrm{d}$ & - & (d) & - & ND \\
\hline Arabinose & + & - & - & $\mathrm{d}$ & - & $\mathrm{d}$ \\
\hline Arbutine & $\mathrm{d}$ & - & - & - & - & ND \\
\hline Cellobiose & $\mathrm{d}$ & $\mathrm{d}$ & - & (d) & - & $\mathrm{d}$ \\
\hline Fructose & + & + & - & + & + & + \\
\hline Galactose & + & $\mathrm{d}$ & $\mathrm{d}$ & + & + & $\mathrm{d}$ \\
\hline Glucose & + & + & + & + & + & + \\
\hline Lactose & (d) & + & + & (d) & + & - \\
\hline Maltose & + & + & $\mathrm{d}$ & + & + & - \\
\hline Mannitol & $\mathrm{d}$ & $\mathrm{d}$ & - & (d) & - & - \\
\hline Mannose & + & d & - & + & $\mathrm{d}$ & d \\
\hline Melibiose & $\mathrm{d}$ & d & - & + & $\mathrm{d}$ & d \\
\hline Raffinose & $\mathrm{d}$ & $\mathrm{d}$ & - & $\mathrm{d}$ & $\mathrm{d}$ & - \\
\hline Ribose & + & ND & ND & ND & ND & ND \\
\hline
\end{tabular}




\begin{tabular}{|c|c|c|c|c|c|c|}
\hline \multirow[b]{2}{*}{ Caractères } & \multicolumn{3}{|c|}{ 1. L. mesenteroides, subsp. } & \multirow{2}{*}{$\begin{array}{l}\text { 2. L. pa- } \\
\text { ramesen- } \\
\text { teroides }\end{array}$} & \multirow[b]{2}{*}{$\begin{array}{l}\text { 3. L. } \\
\text { lactis }\end{array}$} & \multirow[b]{2}{*}{ L. oenos } \\
\hline & $\begin{array}{l}1 \mathrm{a} . \\
\text { mesente- } \\
\text { roides }\end{array}$ & $\begin{array}{l}1 \text { b. dex- } \\
\text { tranicum }\end{array}$ & $\begin{array}{l}1 \text { c. cre- } \\
\text { moris }\end{array}$ & & & \\
\hline Salicine & $\mathrm{d}$ & d & - & - & $\mathrm{d}$ & $\mathrm{d}$ \\
\hline Saccharose & + & + & - & + & + & - \\
\hline Trehalose & + & + & - & + & - & + \\
\hline Xylose & $\mathrm{d}$ & $\mathrm{d}$ & - & $\mathrm{d}$ & - & $\mathrm{d}$ \\
\hline $\begin{array}{l}\text { Hydrolyse } \\
\text { de l'esculine }\end{array}$ & $d$ & $d$ & - & & - & \\
\hline $\begin{array}{l}\text { Facteurs } \\
\text { de croissance }\end{array}$ & & & & & & \\
\hline Uracile & - & - & + & - & - & - \\
\hline \multicolumn{7}{|l|}{$\begin{array}{l}\text { Guanine + } \\
\text { adenine } \\
+ \text { xanthine }\end{array}$} \\
\hline + uracile & - & d & + & $\mathrm{d}$ & - & + \\
\hline Riboflavine & $\mathrm{d}$ & $\mathrm{d}$ & + & + & + & + \\
\hline Pyridoxal & d & d & + & + & - & + \\
\hline Acide folique & d & d & + & + & - & + \\
\hline $\begin{array}{l}\text { "Tomato juice } \\
\text { factor»" }\end{array}$ & - & - & - & - & - & d \\
\hline \multicolumn{7}{|l|}{$\begin{array}{l}\text { Destruction du } \\
\text { « tomato juice }\end{array}$} \\
\hline factor $»$ & - . & - & - & - & - & d \\
\hline \multicolumn{7}{|l|}{ Formation } \\
\hline $\begin{array}{l}\text { Dissimilation } \\
\text { du citrate en présence } \\
\text { de sucre }\end{array}$ & & & & & & \\
\hline fermentescible & d & d & + & $\mathrm{d}$ & $\mathrm{d}$ & d \\
\hline \multicolumn{7}{|l|}{ Dissimilation } \\
\hline sans sucre & $\mathrm{d}$ & - & - & d & - & ND \\
\hline avec sucre & $\mathrm{d}$ & - & - & $\mathrm{d}$ & - & + \\
\hline \multicolumn{7}{|l|}{ Lait supplémenté } \\
\hline Acide, coagulé & $\mathrm{d}$ & d & $\mathrm{d}$ & $\mathrm{d}$ & $\mathrm{d}$ & - \\
\hline Réduction & $\mathrm{d}$ & d & - & $\mathrm{d}$ & (d) & $\mathrm{d}$ \\
\hline Gaz & $\mathrm{d}$ & $\mathrm{d}$ & - & - & - & - \\
\hline \multicolumn{7}{|l|}{$\begin{array}{l}\text { Croissance } \\
\text { en présence de : }\end{array}$} \\
\hline $\begin{array}{l}\text { en présence de : } \\
3,0 \% \mathrm{NaCl}\end{array}$ & + & d & - & d & d & ND \\
\hline $6,5 \% \mathrm{NaCl}$ & d & - & - & d & - & ND \\
\hline \multicolumn{7}{|l|}{ Croissance à $\mathrm{pH}$ : } \\
\hline 4,8 (initial) & - & - & - & d & - & + \\
\hline 6,5 (initial) & + & + & + & + & + & d \\
\hline \multirow{2}{*}{$\begin{array}{l}\text { Croissance à } 37^{\circ} \mathrm{C} \\
\text { pH final en bouillon } \\
\text { glucosé }\end{array}$} & d & + & - & d & + & $\mathrm{d}$ \\
\hline & 4,5 & 4,5 & 5,0 & 4,4 & 4,7 & ND \\
\hline - : négatif & $\mathrm{d}$ : réac & n lente & ND : non d & miné. & & \\
\hline
\end{tabular}


GaRvie (1984) propose de regrouper les bactéries lactiques hétérofermentaires (Leuconostocs et lactobacilles hétérofermentaires) en quatre sous-genres. Selon cet auteur : la classification est une science toujours en développement et au fur et à mesure que nos connaissances progressent, elle peut changer pour s'adapter aux nouvelles vérités scientifiques.

\section{Ecologie des Leuconostocs}

Les Leuconostocs sont très répandus dans la nature; dans cette étude nous avons surtout cité les références ayant trait aux produits laitiers ou au matériel ou produits susceptibles de contaminer le lait et les produits laitiers.

\section{Le lait}

Les Leuconostocs sont fréquemment rencontrés dans le lait. ABD-ELMalek et Gibson (1948) ont essentiellement trouvé Str. kefir (L. lactis) et Str. citrovorus ( $L$. cremoris) comme microorganismes représentant les streptocoques hétérofermentaires dans le lait. EL-GENDY et al. (1983) ont isolé principalement $L$. paramesenteroides de lait cru sale. Dans le lait utilisé pour la fabrication du fromage blanc saumuré, CHOMAKov (1975) a isolé des Leuconostocs appartenant principalement à l'espèce $L$. mesenteroides. Nunez et al. (1984) ont montré que dans les laits de brebis crus réfrigérés, $L$. dextranicum était l'espèce de bactéries psychrotrophes Gram-positive la plus fréquemment isolée. MARET et Sozzi (1976) ont isolé L. cremoris, L. lactis et L. mesenteroides de lait d'alpage utilisé pour la fabrication de fromage à raclette. FAtichenti et al. (1979) ont montré que dans les laits de chèvre de Sardaigne les Leuconostocs étaient présents en nombre limité et qu'ils appartenaient essentiellement à l'espèce $L$. mesenteroides. NunEz (1978) cite la présence de Leuconostocs dans le lait utilisé pour la fabrication du fromage de Cabrales et Millet et al. (1978) dans le lait utilisé pour la fabrication du fromage de Cantal.

Enfin rappelons que dans les différentes classifications citées au chapitre précédent de nombreuses souches de Leuconostocs ont été isolées du lait.

\section{Les levains}

Les Leuconostocs entrent couramment dans la composition de levains utilisés pour la fabrication de nombreux produits laitiers, tels le fromage de Roquefort (Devoyod et al., 1974 a et b), le fromage de Laguiole (DidienNe et al., 1978), le fromage de Manchego (Ramos et al., 1981). Mostert et HusMANN (1975) ont trouvé des Leuconostocs dans des levains commerciaux utilisés pour la fabrication du Gouda en Afrique du Sud. Sur 460 souches isolées de levains commerciaux HolzAPFEL et KRIEL (1973) ont identifié 33 microorganismes comme appartenant au genre Leuconostoc. Sur 140 Leuconostocs isolés de levains, RIEmelt (1982) en classa 7 dans l'espèce L. cremoris.

En dehors de tout problème lié à l'identification des espèces de Leuconostocs, il semblerait que dans la flore des levains utilisés en technologie laitière, L. cremoris soit moins représenté actuellement qu'il y a plusieurs années. Cela est en partie dû au fait que pour la production d'arôme les utilisateurs emploient de préférence Streptococcus diacetylactis, microorganisme qui peut à la fois acidifier et produire du diacétyle, tandis qu'il est nécessaire d'associer un streptocoque acidifiant à $L$. cremoris. 


\section{La crème et le beurre}

Les données que nous possédons concernant la flore naturelle de la crème et du beurre sont rares. ORLA-JENSEN et al. (1926) mentionnent parmi les bactéries d'arôme du beurre, les streptocoques à formation de capsules. Les bactéries appartenant à ce groupe sont aptes à former un peu d'acide acétique, d'acide carbonique et d'autres produits volatils; mais elles ne peuvent produire de l'acide lactique en quantité notable. Très tôt dans la technologie beurrière, les crèmes ont été maturées avec utilisation de levains.

D'après DoRner et al. (1952) la microbiologie de la crème n'offre que peu de différences avec celle du lait. Quant à DEMETER (1956), dans son traité sur la microbiologie du beurre, il cite la présence, dans la crème maturée et le beurre, de bactéries d'arôme : Str. diacetylactis, Str. citrophilus, Bc. cremoris et Bc. bovis. Mais leur présence dans le beurre est faible car déjà dans les levains et la crème maturée, ils ne représentent que quelques \% de la quantité des bactéries lactiques. Rappelons que $L$. cremoris est considéré actuellement comme une sous-espèce de $L$. mesenteroides et que d'après GaRviE (1976), Leuconostoc cremoris aurait évolué à partir de Leuconostoc mesenteroides ou à partir de Leuconostoc dextranicum dans l'environnement particulier de la laiterie.

\section{Les produits fermentés}

Parmi les laits fermentés dont la flore microbienne contient des Leuconostocs, nous devons citer le kéfir. Dès 1918, Evans avait donné le nom de Streptococcus kefir à des streptocoques hétérofermentaires isolés de grains de kéfir. Dans une étude sur la composition et la structure des grains de kéfir, OLsSon (1981) a montré que la flore microbienne était complexe et qu'à côté de Leuconostoc kefir on trouvait Streptococcus lactis, Lactobacillus brevis, L. acidophilus, L. caucasium, Saccharomyces lactis, Sacch. carlsbergensis, Sacch. kefir, Candida tenuis, C. pseudotropicalis, Torula kefir et Acetobacter rancens.

Au cours d'une étude similaire KRUSCH (1984) a montré que la flore microbienne variait avec l'origine des grains de kéfir. $L$. cremoris a été détecté dans les différents échantillons, régulièrement associé à $L$. dextranicum et/ou à L. paramesenteroides. Par contre L. lactis (ex Streptococcus kefir) n'a été isolé que sporadiquement.

Pour Pidoux (1985), la population fixe du grain de kéfir est composée de $L b$. brevis (ou d'une espèce voisine), Lb. casei, L. mesenteroides et Saccharomyces (ou Torulopsis).

\section{Les fromages}

En dehors de toute addition de levains contenant des Leuconostocs, la présence de ces microorganismes a été reconnue dans de nombreux fromages fabriqués à partir de lait de vache, de brebis ou de chèvre. On peut citer le fromage de Cheddar (SHERwood, 1939), de Cabrales (Nunez, 1978), de Manchego (Ordonez et al., 1978), de Tafi (DE Giori et al., 1983), de Roncal (Ordonez et al., 1980), de Pannerone (OtTogalli et al., 1975), de fromages 
de chèvres sardes (FATICHENTI et al., 1979), de fromages de Roquefort (Devoyod et Muller, 1969), de fromages de Cantal (Millet et al., 1974, 1978), de fromages de Saint-Nectaire (Didienne et al., 1978), etc.

Dans le tableau 3 nous avons donné, à titre d'indication, la teneur en Leuconostocs de quelques fromages français fabriqués à partir de lait cru.

Dès 1939, Sherwood, dans une étude sur la flore microbienne du fromage de Cheddar néozélandais, remarquait que $L$. mesenteroides était l'espèce la plus fréquemment rencontrée devant $L$. dextranicum. Cet auteur s'étonnait de l'absence de $L$. citrovorus dans des échantillons de fromages analysés alors que ce microorganisme était très commun dans les cultures de levain. Ces résultats ont été confirmés sur d'autres types de fromages, tels le Roquefort (DEvoroD et Muller, 1969), le fromage de Cabrales (Nunez et Medina, 1979) ou les fromages de chèvre de Sardaigne (FATICHENTI et al., 1979). Les Leuconostocs isolés de quelques fromages français (cf. tabl. 3) appartenaient essentiellement aux espèces $L$. mesenteroides et $L$. dextranicum.

\section{TABLEAU 3}

Teneur en leuconostocs de quelques fromages français fabriqués à partir de lait cru Quantities of Leuconostoc numbered in some French cheeses made with raw-milk (Samples come from ready-to-eat cheeses)

\begin{tabular}{l|c}
\hline \multicolumn{1}{c|}{ Fromages } & $\begin{array}{c}\text { Niveau } \\
\text { (/g de fromage) }\end{array}$ \\
\hline Charollais & $10^{8}-10^{9}$ \\
Crottin de Chavignol & $10^{7}-10^{8}$ \\
Reblochon & $10^{5}-10^{6}$ \\
Pont-l'Evêque & $10^{8}-10^{9}$ \\
Coeur de Bray & $10^{8}$ \\
Abbaye d'Entrames & $10^{7}$ \\
Tamié & $10^{7}$ \\
Livarot & $10^{4}$ \\
Cantal & $10^{6}-10^{7}$ \\
Laguiole & $10^{7}-10^{8}$ \\
Roquefort & $10^{6}-10^{7}$ \\
Fourme de Montbrison & $10^{6}-10^{7}$ \\
\hline
\end{tabular}

Les échantillons ont été prélevés sur des fromages prêts à être consommés.

Les Leuconostocs ont été impliqués dans des défauts de gonflements précoces rencontrés dans le fromage de Hollande (GAlesloot, 1950), de Cheddar (Overcast et Albrecht, 1952), dans le caillé de fromage de cottage (SANDine et al., 1959) ou de gonflements tardifs dans le fromage de SaintNectaire (Didienne et Devoyod, 1978). 


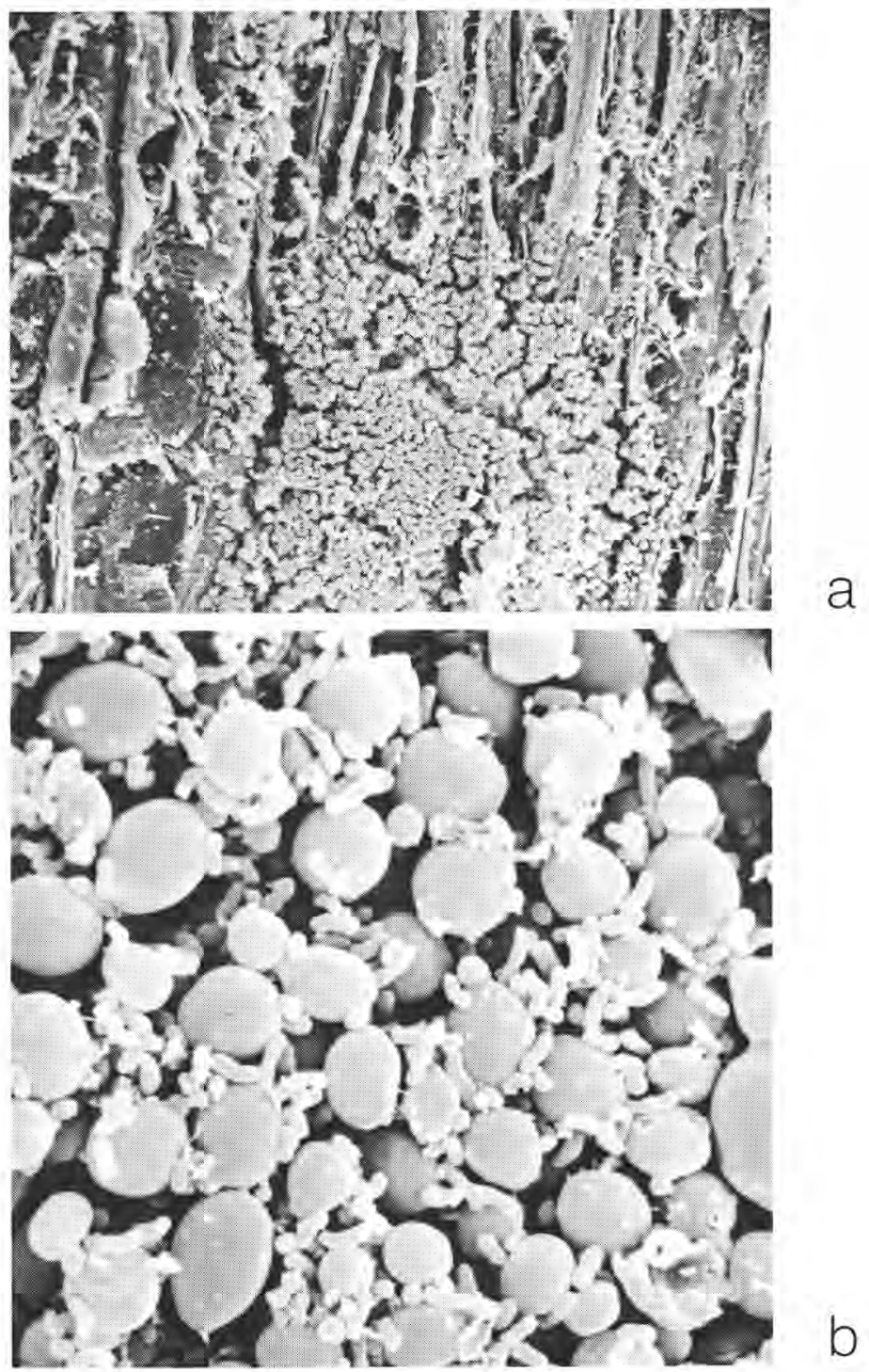

Fig. 1

Fixation des Leuconostocs sur récipients en bois. (Examen en microscopie électronique de balayage).

a) Grossissement 600 fois.

b) Détail de la vue précédente : grossissement 6000 fois.

(On distingue les Leuconostocs sur les cellules de levures).

Photos Micheline Rousseau - Christiane Le Gallo INRA - C.R. Jouy-en-Josas

Adhesion of Leuconostocs on wooden tools used in traditional cheesemaking.

(Examination by scanning electron microscopy). 


\section{Le matériel}

Bien que certaines souches de $L$. mesenteroides aient été utilisées dans les études d'adhésion aux surfaces (LAKEW, 1982; BELLON-FONTAINE et CERF, 1986) il n'existe guère de références sur la recherche de la présence de ces microorganismes dans la flore de contamination du matériel utilisé en technologie laitière et fromagère. Cela est vraisemblablement dû au fait qu'étant non pathogènes, thermosensibles et ne possédant pas d'enzymes protéolytiques ou lipolytiques thermorésistantes connues comme le sont celles des Pseudomonacées par exemple, les Leuconostocs n'intéressent ni les hygiénistes, ni les technologues!

Millet et al. (1984) ont montré qu'en fabrication traditionnelle de fromages à pâte pressée demi-dure, type Cantal, les récipients en bois utilisés étaient d'abord colonisés par les levures sur lesquelles se fixaient les Leuconostocs (fig. 1). L'ensemencement du lait de fabrication par ces récipients se fait en moins de dix minutes de contact (Devoyod et al., 1987).

En ce qui concerne les moules utilisés dans la fabrication des fromages de chèvre fermiers, type Crottin de Chavignol ou type Sainte-Maure, les Leuconostocs sont "fixés » directement sur la paroi interne des moules, que ces moules soient en terre vernissée, en fer galvanisé ou en matière plastique (fig. 2).

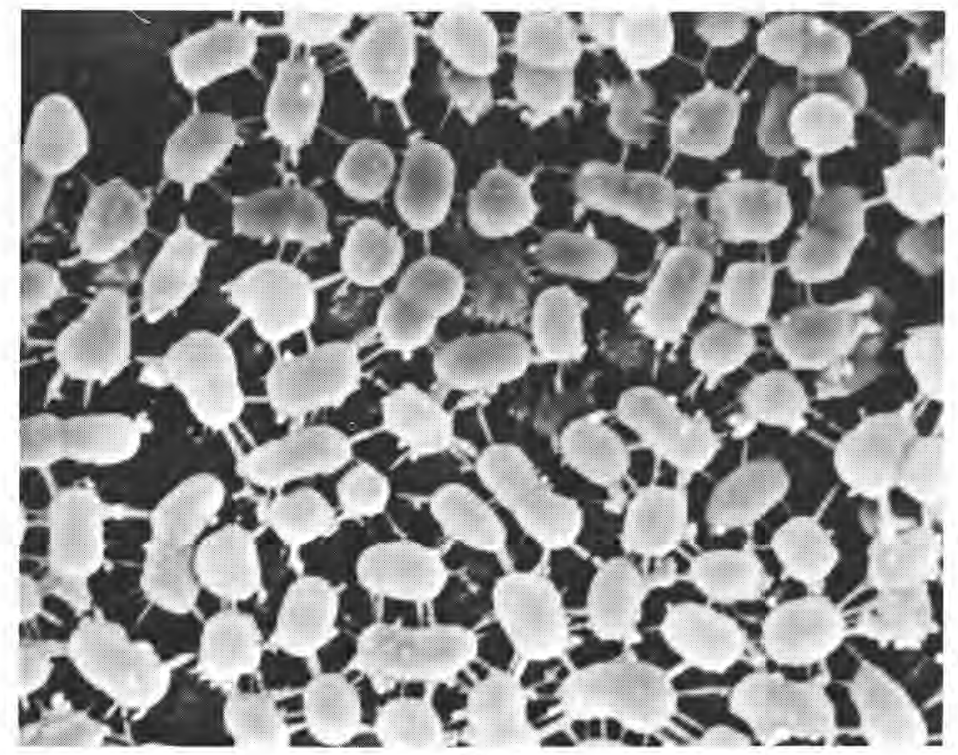

Fig. 2

Fixation des Leuconostocs sur les moules en grès-vernissé. (Examen en microscopie électronique de balayage).

Grossissement 11 500fois.

Photo Micheline Rousseau - Christiane Le Gallo INRA - C.R. Jouy-en-Josas

Adhesion of Leuconostocs on glazed sandstone moulds.

(Examination by scanning electron microscopy). 


\section{Ensilage}

Langston et Bouma (1960) dans une étude sur les cocci isolés de l'ensilage ont montré que parmi les espèces hétérofermentaires présentes, L. mesenteroides était l'espèce la plus représentative et que les souches de Leuconostocs non productrices de dextranes retrouvaient ce caractère après plusieurs repiquages en milieu enrichi. Grazia et Suzzi (1984) ont isolé L. mesenteroides d'échantillons d'ensilage de maïs et de luzerne prélevés dans les fermes de la région d'Emilie-Romagne. $L b$. buchneri était le microorganisme le plus fréquemment isolé. Pour Kroulik et al. (1955) les bactéries lactiques se multiplient dans le fourrage coupé juste avant l'ensilage. LANGSTON et al. (1962) ont montré que dans les ensilages de dactyle et de luzerne de très bonne qualité, la fermentation débutait sous l'action des streptocoques, se poursuivait grâce aux pédiocoques et aux Leuconostocs et qu'elle se terminait avec les lactobacilles. Sur 400 bactéries lactiques isolées de plantes, StiRling et Whittenbury (1963) ont trouvé $80 \%$ de Leuconostocs, environ $10 \%$ de pédiocoques et le reste comme étant des lactobacilles. Les Leuconostocs étaient les plus largement distribués. Ils se trouvaient sur les gaines et les brins d'herbe partiellement desséchés et, sur les feuilles abîmées des arbres, etc. Pour ces auteurs, la présence des Leuconostocs est vraisemblablement associée à la libération de nutriments à partir des tissus végétaux abîmés ou en pourriture.

Selon Fenton (1987), parmi le matériel utilisé au cours des opérations d'ensilage, la faucheuse est la principale cause de contamination en Leuconostocs. Parmi ces microorganismes $L$. mesenteroides ssp. mesenteroides est l'espèce la plus représentative.

\section{Divers}

$L$. oenos se trouve étroitement associé au vin. $L$. mesenteroides a été isolé de nombreux produits végétaux fermentés (STAMER et al., 1971; CHEN et al., 1983) ou non (Lonvaud-Funel et Strasser de SAAD, 1982) ainsi que de produits d'origine animale (REDdy et al., 1970 ; CHRISTOPHeR et al., 1979 ; SAvell et al., 1981).

\section{Métabolisme des Leuconostocs}

\section{Fermentation des hexoses}

Les bactéries lactiques sont capables de produire de l'acétaldéhyde et de l'éthanol à partir du glucose (LeEs et JAGO, 1976). Trois voies principales existent pour la synthèse de l'acétaldéhyde à partir du glucose : la voie d'Embden-Meyerhof, celle d'Etner Doudoroff et la voie des hexoses monophosphates. Les Leuconostocs fermentent le glucose en utılisant cette troisième possibilité. Ils clivent le xylose-5-phosphate en acétyl-phosphate et en glycéraldéhyde-3-phosphate par action de la phosphocétolase (GoldBerg et al., 1966).

Les Leuconostocs ne peuvent pas décarboxyler directement, comme certains microorganismes, le pyruvate en acétaldéhyde car ils ne possèdent pas de pyruvate décarboxylase (DE Moss et al., 1951). La réduction de l'acétate et de 
l'acétaldéhyde est l'un des mécanismes principaux de la réoxydation de pyridine nucléotide réduite chez L. mesenteroides (Gales Loot, 1962). L. mesenteroides possède deux alcool-déshydrogénases (DE Moss, 1954).

Compte tenu des études effectuées sur $L$. mesenteroides ou $L$. dextranicum, il est possible de donner le schéma simplifié suivant de la fermentation des hexoses par les Leuconostocs:

hexose ........ $\rightarrow$ phosphogluconate $+2 \mathrm{H}$
phosphogluconate $\ldots \ldots \rightarrow \mathrm{CO}_{2}+$ pentose-phosphate $+2 \mathrm{H}$
pentose-phosphate $\ldots \ldots \rightarrow$ acétylphosphate + triose-phosphate
triose-phosphate $\ldots \ldots \rightarrow$ acide pyruvique $+2 \mathrm{H}$
acide pyruvique $+2 \mathrm{H} \ldots \rightarrow$ acide lactique
acétylphosphate $+2 \mathrm{H} \ldots \rightarrow$ acétaldéhyde
acétaldéhyde $+2 \mathrm{H} \ldots . \rightarrow$ éthanol
soit : hexose $\ldots \ldots \ldots \rightarrow \mathrm{CO}_{2}+$ éthanol + acide lactique

L'acétate est le principal produit terminal du métabolisme des hexoses des souches de Leuconostocs par voie oxydative (ITo et al., 1983). Selon Lucey et Condon (1986) les cultures aérées de Leuconostocs croissent plus vite et produisent plus de biomasse, aux dépens du glucose et d'autres sucres, que les cultures non aérées. Ces dernières ne produisent que peu ou pas d'acétate.

Bocquien (1987) a montré la présence d'une $\alpha$-galactosidase chez une souche de Leuconostoc sp. Nous avons mesuré l'activité $\alpha$-galactosidasique de 36 souches de Leuconostocs producteurs de dextranes; 17 souches (soit $47,2 \%$ ) ont donné un résultat positif.

\section{Fermentation des citrates et acides carboxyliques}

La fermentation des citrates est un phénomène important chez $L$. cremoris (ex $L$. citrovorum) et $L$. lactis puisqu'elle est en relation très étroite avec l'activité aromatique de ces microorganismes.

La voie métabolique qui conduit des citrates au diacétyle est la même que celle suivie par Str. lactis subsp. diacetylactis (Kempler et McKay, 1981).

Les Leuconostocs ne peuvent utiliser le citrate comme seule source d'énergie (comme Str. lactis subsp. diacetylactis), ils ne peuvent le métaboliser qu'en présence d'un sucre fermentescible.

La pénétration du citrate dans la cellule fait intervenir une citrateperméase active à $\mathrm{pH}$ inférieur à 6 . Le système de transport du citrate diffère de celui de la $\beta$-galactoside perméase d'Escherichia coli car nécessitant une énergie métabolique dans des conditions qui ne permettent pas l'accumulation intracellulaire de la substance transportée (HaRveY et Collins, 1962).

A l'intérieur de la cellule, le citrate est clivé en acétate et en oxaloacétate par action d'une citrate lyase ou citritase (HARंveY et ColLins, 1961). L'activité de la citrate lyase chez Leuconostoc lactis augmente en même temps que la croissance cellulaire se développe et n'est décelable que dans des cultures se multipliant en présence de citrate (Mellerick et Cogan, 1981). C'est donc une enzyme inductible, à l'inverse de la citrate lyase de Str. lactis subsp. diacetylac- 
tis qui, elle, est constitutive (Harvey et Collins, 1961; Cogan, 1981). Par contre chez L. lactis, comme chez Str. lactis subsp. diacetylactis, le $\mathrm{pH}$ optimum de cette enzyme est de 6,0 .

L'activité de cette enzyme nécessite la présence de cations bivalents, principalement $\mathrm{Mn}^{++}$et $\mathrm{Mg}^{++}$.

Une oxaloacétate décarboxylase scinde l'oxaloacétate en pyruvate et $\mathrm{CO}_{2}$. Le pyruvate formé est lui-même décarboxylé et donne un complexe aldéhydethiaminepyrophosphate (aldéhyde-TPP) ou «aldéhyde active ».

Par réaction avec une molécule de pyruvate, ce complexe forme de l' $\alpha$ acétolactate. Cette réaction est catalysée par une acétolactate-synthase (CogAN et al., 1984). L'activité de cette enzyme ne nécessite pas la présence d'ions $\mathrm{Mn}^{++}$.

Chez de nombreuses bactéries, il existe deux acétolactate-synthases, l'une qui intervient dans la biosynthèse de la valine et de l'isoleucine avec un $\mathrm{pH}$ optimum de 8,0 et l'autre qui intervient dans la production d'acétoïne avec un $\mathrm{pH}$ optimum de 6,0. L'acétolactate-synthase de $L$. lactis a un $\mathrm{pH}$ optimum qui se situe entre 5,0 et 6,0 ; elle peut être considérée comme intervenant dans la production d'acétoïne car l'acétoïne est un produit de la croissance de L. lactis à $\mathrm{pH}$ acide (COGAN et al., 1981). De plus les Leuconostocs ne peuvent pas posséder une acétolactate-synthase qui intervient dans la biosynthèse de la valine et de l'isoleucine puisque leur croissance exige de la valine et encore plus de l'isoleucine (GARVIE, 1967b).

Chez L. lactis (Mellerick et Cogan, 1981), l'activité de l'acétolactatesynthase continue à diminuer au fur et à mesure que la croissance augmente, mais le niveau est supérieur pour les cellules qui se multiplient en présence de citrate, ce qui démontre que l'enzyme est en partie inductible. Ce résultat diffère de celui obtenu avec Str. lactis subsp. diacetylactis chez qui l'acétolactate-synthase est constitutive (COGAN, 1981).

Par action d'une acétolactate décarboxylase, l' $\alpha$-acétolactate donne de l'acétoïne et du $\mathrm{CO}_{2}$. SPECKMAN et Coluins (1968) ont montré que le complexe acétaldéhyde-TPP pouvait réagir avec l'acétyl-coenzyme $\mathrm{A}$ et donner du diacétyle.

Il existe donc deux voies distinctes de production d'acétoïne, par les Leuconostocs : soit par décarboxylation de l'oxaloacétate, soit par réduction du diacétyle.

Selon Harvey et Collins (1963) la production d'acétoïne sert de mécanisme de détoxification par élimination du pyruvate intracellulaire en excès, non nécessaire à la synthèse du matériel cellulaire. En l'absence de citrate peu ou pas d'acétoïne est produite puisque tout le pyruvate produit à partir des sucres sert à régénérer le NAD permettant à la glycolyse de se poursuivre (HARvey et Collins, 1961). Les bactéries lactiques hétérofermentaires produisent de l'acétoïne et du diacétyle en milieu acide mais métabolisent le citrate sans donner, ou peu, d'acétoïne, en milieu neutre (COGAN et al., 1981; Cogan, 1975). Une des hypothèses avancées (Drinan et al., 1976) pour expliquer ces résultats apparemment contradictoires est que le citrate est utilisé dans quelque autre voie métabolique au cours de la croissance (peut-être 
synthèse de lipides) et que ce n'est qu'en absence de croissance (conditions acides) que le diacétyle et l'acétoïne sont produits en certaine quantité. A cet égard, BRANEN et KEENAN (1971) ont trouvé qu'en culture agitée Lactobacillus casei produisait plus de diacétyle et d'acétoïne, par contre la croissance était moindre qu'en culture non agitée.

Quant aux réductions successives du diacétyle en acétoïne puis en 23 butylène-glycol, réactions catalysées par une diacétyle réductase et une acétoïne-réductase, enzymes réprimées en partie par le citrate, elles permettent la régénération du NAD cellulaire avec formation simultanée de molécules neutres non toxiques pour la cellule.

LiNDSAY et al. (1965) ont montré que l'acétaldéhyde produite par Str. diacetylactis qui donnait un goût défectueux au beurre, disparaissait en présence de $L$. citrovorum et que la quantité de diacétyle apparu correspondait à la quantité d'acétaldéhyde disparue ; d'où l'hypothèse que l'acétaldéhyde pouvait être un précurseur dans la synthèse du diacétyle chez les Leuconostocs.

En utilisant de l'acétaldéhyde marquée (acétaldéhyde $1-2 \cdot{ }^{14} \mathrm{C}$ ), CoLlins et SPECKMAN (1974) ont montré qu'ajoutée à un bouillon glucose-citrate cette substance était convertie en éthanol par $L$. citrovorum, tandis que l'acétoïne, le diacétyle et l'acide acétique formés n'étaient pas radioactifs. D'après ces auteurs, l'aldéhyde ajoutée augmentait la production d'acétoöne et de diacétyle en permettant une plus grande disponibilité de l'hydroxyéthylamine pyrophosphate et, de l'acétyl-coenzyme $\mathrm{A}$, et ainsi stimulait la croissance en convertissant une plus grande quantité de l'acétyl-coenzyme A et de l'acétyl-phosphate en acétate et adénosine $5^{\prime}$-triphosphate.

Le schéma du métabolisme des citrates chez L. citrovorum ( $L$. cremoris) est donné à la figure 3 .

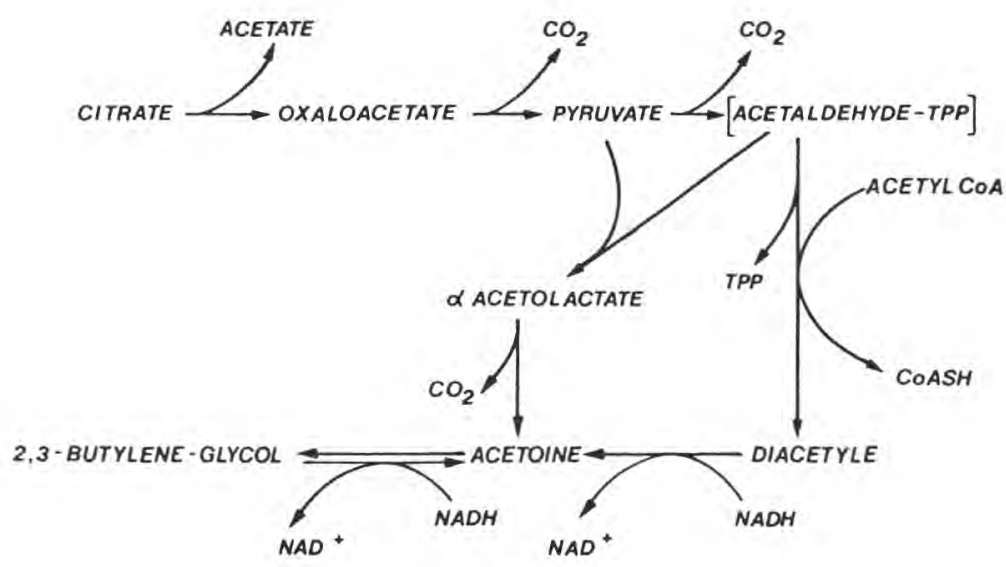

Fig. 3

Métabolisme des citrates chez Leuconostoc cremoris (d'après Cogan et al., 1981).

Citrate metabolism by Leuconostoc cremoris. 
D'autres espèces de Leuconostocs sont capables d'utiliser le citrate mais sans produire de diacétyle ni d'acétoïne. La presque totalité des 210 souches de $L$. mesenteroides ssp. mesenteroides et $L$. mesenteroides ssp. dextranicum isolées par nous des produits laitiers, du matériel et de la vaisselle laitière, donnaient une réaction positive lorsqu'elles étaient cultivées sur le milieu de KeMPLer et McKay (1980) mais elles ne produisaient pas d'acétoïne lorsque nous utilisions la technique de SwartLing (1951). Par contre les deux souches de Str. lactis ssp. diacetylactis et L. cremoris utilisées comme témoins donnaient, dans les mêmes conditions de culture, un résultat positif. En technologie laitière il est reconnu que le principal rôle des Leuconostocs est de produire des composés d'arôme ; c'est la raison pour laquelle les voies métaboliques d'utilisation du citrate par $L$. mesenteroides ssp. mesenteroides ou $L$. mesenteroides ssp. dextranicum n'ont pas été étudiées.

\section{Fermentation d'autres acides carboxyliques}

RADLER et BröHL (1984) ont montré que L. oenos et L. mesenteroides étaient capables de métaboliser plusieurs acides carboxyliques : fumarate, gluconate, malate, 2-oxoglutarate et pyruvate. Ce dernier acide est métabolisé sans formation de diacétyle ou d'acétoïne comme le fait $L$. cremoris (HegazI et Abo-Elnaga, 1980).

La transformation de l'acide malique en $\mathrm{L}(+)$-lactate et $\mathrm{CO}_{2}$ (fermentation malolactique) est importante en œnologie. Si $L$. mesenteroides possède bien une enzyme malolactique, son rôle pratique se trouve restreint du fait que ce microorganisme ne se développe pas, comme $L$. oenos, à bas $\mathrm{pH}$ et en présence d'éthanol.

\section{Production de dextranes}

De nombreux microorganismes sont capables de produire des exopolysaccharides c'est-à-dire des polysaccharides à l'extérieur de la paroi cellulaire qui sont, soit attachés à cette paroi sous forme de capsule, soit excrétés dans l'environnement extracellulaire sous forme de gomme. SutHerLand (1982) a classé les exopolysaccharides en 5 groupes selon leur composition. Le premier groupe comprend les dextranes et polysaccharides voisins. Ce sont des homopolysaccharides produits par des bactéries utilisant la saccharose comme substrat spécifique. Les bactéries qui synthétisent de tels polymères comprennent, entre autres, des espèces du genre Streptococcus et Leuconostoc. En l'absence de saccharose (ou de substrats très voisins) ces bactéries peuvent se développer mais ne peuvent former de polysaccharides. Les dextranes ont une grande importance dans l'industrie, la médecine et la recherche et de nombreuses études ont été faites sur la production de dextranes par $L$. mesenteroides, mais toutes ces études portent essentiellement sur des souches isolées de sucrerie ou plus exactement de matière première de sucrerie (mélasse ou bagasse). Les polymères produits varient énormément dans la longueur des chaînes et le degré de liaison.

L'activité des dextrane-sucrases de $L$. mesenteroides a pour résultat la formation de dextranes de bas poids moléculaire et d'oligosaccharides (RoBYT et WALSETH, 1978). Les dextrane-sucrases de L. mesenteroides sont inductibles (Kobayashi et Matsuda, 1974) et de ce fait ne peuvent être produites en 
l'absence de saccharose à l'inverse de ce que l'on rencontre pour les dextranesucrases de Str. sanguis et Str. mutans. Par examen au microscope électronique BROOKER (1977) a montré que la paroi cellulaire de $L$. mesenteroides qui présente la structure classique à trois couches des bactéries Gram-positives lorsque ce microorganisme est cultivé en bouillon MRS (DE MAN et al., 1960) est modifiée en présence de saccharose. Après deux heures de contact, il se forme une couche uniforme à la surface de la paroi cellulaire (110 à $130 \mathrm{~nm}$ d'épaisseur). Pour 85 à $90 \%$ des cellules maintenues en présence de saccharose aucun changement apparent n'est notable, par contre les autres cellules commencent à accumuler des dextranes capsulaires insolubles à la surface de cette couche uniforme. Après 18 heures, ces cellules produisent une capsule (diamètre maximum $6 \mu \mathrm{m}$ ) composée principalement d'un ample réticulum de filaments fins. Pour Brooker (1976) la couche extérieure dérive du dextrane globulaire de la capsule selon un processus de dispersion. Cette couche superficielle des cellules croissant en présence de saccharose, représente un complexe dextrane fixé à la cellule. Les cellules ne présentant pas cette capsule produisent du dextrane relativement soluble ce qui avait été déjà noté par SMITH (1970).

D'après Garvie (1984), L. mesenteroides se développe bien sur milieu contenant du saccharose et forme de grandes quantités de dextrane, tandis que $L$. dextranicum est moins actif et forme seulement de petites quantités de dextrane. Parmi les Leuconostocs producteurs de dextrane que nous avons étudiés, nous avons pu différencier, parmi $L$. mesenteroides ssp. mesenteroides, deux types de colonies sur le milieu au saccharose de Mayeux, SANDine et ELLIKER (1962) :

a) de grosses colonies gluantes, devenant rapidement confluantes au fur et à mesure que l'incubation se prolonge ;

b) de petites colonies ( $2 \mathrm{~mm}$ environ de diamètre) bombées et adhérant fortement à la surface de la gélose.

Ces différences morphologiques correspondent à des différences nettes dans la viscosité mesurée après incubation en bouillon saccharosé à $10 \%$ (quelques centipoises pour les Leuconostocs de la première catégorie, viscosité supérieure à 30 centipoises pour les autres). Les souches du $2^{\mathrm{e}}$ groupe ne représentent qu'une petite fraction des Leuconostocs producteurs de dextrane isolés des produits laitiers, de l'ordre de 2 à $3 \%$.

Coté et RoBYT (1983) ont montré que L. mesenteroides NRRL B-742 produisait deux $\alpha$-D-glucanes exocellulaires : une fraction $\mathrm{L}$ avec branchement $\alpha$-D- $(1 \rightarrow 4)$ et une fraction S avec branchement $\alpha$-D- $(1 \rightarrow 3)$. Ces auteurs ont montré que le pourcentage de branchement $\alpha$-D- $(1 \rightarrow 3)$ dans la fraction $S$ était variable, dépendant des conditions de synthèse à partir du saccharose par la glucanesucrase et que cette glucanesucrase était également capable de modifier d'autres dextranes de la fraction L. Il est donc possible pour $L$. mesenteroides de produire des dextranes de structure et de composition très différentes d'autant qu'il existe une relation biosynthétique entre les dextranes solubles et les dextranes insolubles produits par une même souche de L. mesenteroides (SмIтH, 1970) et que la dextranesucrase de ce microorganisme peut prendre des formes multiples (Kobayashi et Matsuda, 1986).

La production de dextrane à partir de saccharose est un caractère impor- 
tant de différenciation des espèces de Leuconostoc (Garvie, 1967b). Pederson et Albury (1955) ont montré que des souches de $L$. mesenteroides non productrices de dextranes, souches isolées de choucroute, retrouvaient ce caractère après plusieurs repiquages en milieux acides contenant soit du jus de tomate, soit du jus d'orange. Inversement, des souches productrices de dextrane perdaient ce caractère après plusieurs repiquages successifs dans des milieux de concentration croissante en chlorure de sodium (les dextranesucrases de Leuconostocs sont inductibles). Néanmoins, bien que la différenciation phénotypique entre $L$. mesenteroides et $L$. paramesenteroides soit basée essentiellement sur la production de dextrane, $L$. paramesenteroides ne peut pas être considéré comme un mutant dextrane négatif de $L$. mesenteroides car les études d'hybridation d'ADN (HoNTEBEYRIE et GASSER, 1977) ont montré que $L$. paramesenteroides était une espèce distincte.

\section{Production de substances inhibitrices}

L'antibiose est le résultat d'un antagonisme entre des microorganismes au détriment de l'un d'entre eux. En technologie laitière, l'antibiose est bénéfique dans certains cas, néfaste dans d'autres. Si une association de microorganismes provoque l'inhibition d'un germe pathogène ou d'un organisme capable d'altérer un produit laitier, l'antibiose sera favorable. Par contre, si une association de microorganismes empêche le développement d'organismes utiles, elle sera nuisible. Str. cremoris, Str. lactis, L. cremoris et Str. lactis subsp. diacetylactis, microorganismes communs des levains lactiques, sont capables d'inhiber d'autres bactéries (BABEL, 1977). A cette liste de bactéries lactiques, on peut ajouter $L$. dextranicum (Ross, 1981).

Les Leuconostocs, principalement $L$. cremoris, en association avec des bactéries lactiques mésophiles (GENSKE et BRENEN, 1973) sont capables d'inhiber la croissance de microorganismes pathogènes tel S. aureus (HAINES, 1972) ou de bactéries psychrotrophes (JufFs et BABEL, 1975). Les filtrats de culture sur bouillon MRS de 7 souches de Leuconostocs producteurs de dextranes sur 35 essayées inhibaient la croissance de 2 souches de Pseudomonas fluorescens.

MATHER et BABEL (1959) ont ajouté un mélange composé en poids d'une part et demie de crème à $20 \%$ et d'une part d'une culture acidifiée de L. citrovorum à du "cottage cheese" inoculé avec Pseudomonas fragi et Pseudomonas putrefaciens. L. citrovorum (L. cremoris) empêchait ou tout au moins retardait l'aspect visqueux et la protéolyse provoqués par ces Pseudomonas. Les bactéries coliformes étaient également inhibées mais non Geotrichum candidum et Candida pseudotropicalis. Marth (1962), MarTh et Hussong (1963) ont montré que des filtrats de culture sur lait écrémé de $L$. citrovorum inhibaient des souches d'Aerobacter aerogenes, d'Escherichia coli, de Pseudomonas fluorescens et de Pseudomonas fragi et que l'inhibition dépendait à la fois des souches de L. citrovorum cultivées et des souches de microorganismes essayées. Par contre aucun filtrat ne présentait d'action inhibitrice vis-à-vis de Torula glutinis, Saccharomyces cerevisiae, Saccharomyces fragilis et Mycotorula lipolytica.

SORRells et SPECK (1970) ont montré que des filtrats de culture de L. citrovorum inhibaient la croissance de Salmonella gallinarum et à un degré moindre celle de $S$. typhimurium et celle de Staphylococcus aureus. 
Le mécanisme d'inhibition microbienne par L. cremoris et Str. diacetylactis n'est pas encore clairement élucidé. Pour certains (PINHEIRo et al., 1968 ; Minor et MArth, 1970 ; Sorrells et SPECK, 1970 ; Daly et al., 1972) cette action inhibitrice serait due à la présence d'acides organiques et principalement de l'acide acétique: DALY et al. (1972) avaient constaté que le milieu de culture contenant de l'acide acétique inhibait Staphylococcus aureus seulement pour des valeurs de $\mathrm{pH}$ égales ou inférieures à 4,5. La forme non dissociée de l'acide peut être plus inhibitrice que la forme dissociée (Ross, 1981). Or l'acide acétique a un $\mathrm{pK}_{\mathrm{a}}$ de 4,7 et à $\mathrm{pH}=4,5$ il est principalement sous la forme non dissociée, tandis qu'à ce même $\mathrm{pH}$, l'acide lactique est complètement dissocié puisque son $\mathrm{pK}_{\mathrm{it}}$ est de 3,9. D'autres auteurs (DALY et al., 1972) ont émis l'hypothèse que l'eau oxygénée pouvait jouer un rôle dans ces phénomènes d'inhibition. La production d'acides organiques et (ou) d'eau oxygénée ne suffit pas à expliquer l'activité inhibitrice rencontrée. Aussi a-t-il été suggéré la production d'autres substances antimicrobiennes (MATHER et BABel, 1959; Pinheiro et al., 1968). Branen et al. (1975) à partir d'une souche de Str. diacetylactis et d'une souche de L. citrovorum ont purifié un peptide de bas poids moléculaire différant par son spectre antimicrobien, son poids moléculaire et sa localisation extracellulaire, des autres peptides antimicrobiens connus, produits par les bactéries lactiques telle la nisine, la diplococcine ou l'acidophiline.

PARK et MARTH (1972) ont confirmé les résultats d'inhibition vis-à-vis de S. typhimurium, ils ont montré que les couches de Str. lactis et Str. cremoris utilisées étaient plus inhibitrices que les souches de Str. diacetylactis et de L. cremoris.

En utilisant la technique de mise en évidence des bactériocines de Kekessy et Piguet (1970), Orberg et Sandine (1984) ont montré que des souches de Leuconostoc sp. résistant à la vancomycine produisaient une substance antimicrobienne vis-à-vis d'une souche de Str. cremoris.

\section{Plasmides chez les Leuconostocs}

La présence de plasmides chez Leuconostoc a été mise en évidence par O'Sullivan et Daly (1982). Par mutation spontanée, par traitement à l'acridine orange et par plusieurs repiquages à $37^{\circ} \mathrm{C}$, ces auteurs ont obtenu des mutants lac ${ }^{-}$et cit $^{-}$dans la souche X2 de $L$. mesenteroides. Chez ces mutants a été montrée la perte d'un plasmide de $34 \mathrm{Mdal}$ et $10 \mathrm{Mdal}$ respectivement.

ArIAS (1985), en appliquant des traitements antiplasmidiques avec de l'acridine orange et du bromure d'ethidium sur une souche de $L$. dextranicum, a montré que la non-utilisation du citrate, chez le mutant cit $^{-}$, coïncidait avec la perte d'un plasmide de 24 Mdal.

Orberg et SANDine (1984) ont indiqué que plusieurs souches de Leuconostoc résistant à la vancomycine possédaient des plasmides de 27 et 35 Mdal.

L'étude du profil plasmidique des souches de Leuconostoc isolées des produits laitiers (ARIAS, 1985) a mis en évidence la présence de plasmides de petites, moyennes et grandes tailles ( 1,4 - 35 et $80 \mathrm{Mdal}$ respectivement). La complexité du profil plasmidique était plus grande chez $L$. mesenteroides que chez L. cremoris. 
Le nombre de plasmides présents dans une souche ne semblait pas être en corrélation avec le profil biochimique et d'antibiorésistance : ainsi, une souche de $L$. dextranicum qui ne contenait qu'un plasmide de 1,4 Mdal présentait un profil biochimique complexe (18 sucres fermentés).

\section{Leuconostocs et bactériophages}

Selon Garvie (1984), les bactéries qui se développent lentement et qui ne sont pas susceptibles de donner de fortes populations, ne sont pas sensibles aux attaques phagiques. Les Leuconostocs appartiennent à ce type de bactéries. Bien que les Leuconostocs soient utilisées en association avec les streptocoques lactiques dans les levains de fromagerie, ils ne subissent pas, normalement, d'attaques phagiques.

Sozzi et al. (1978a et 1978b) ont décrit un bactériophage de L. mesenteroides (groupe V de GARvie, 1960) isolé d'échantillons de petit lait et de babeurre. Ce phage appartient au groupe B de BRADLEY. Sa multiplication a lieu entre 17 et $33^{\circ} \mathrm{C}$. Son cycle de réplication dure 75 minutes et, dans les meilleures conditions de culture, le rendement dépasse 170 phages par bactérie infectée. Depuis 1974, une souche de L. mesenteroides est utilisée industriellement comme levain dans la fabricatiuon de fromages à pâte persillée sans qu'aucune attaque phagique n'ait été signalée. Pour Garvie (1984), il est possible que les dextranes protègent la bactérie des attaques phagiques. Sozzi et al. (1982) ont cité des difficultés rencontrées dans la fermentation malolactique du vin, difficultés attribuées à la présence de bactériophages de $L$. oenos.

\section{E. Utilisation des Leuconostocs}

Les Leuconostocs rentrent dans la composition de la flore bactérienne des levains lactiques mésophiles. Galesloot et Hassing (1961) puis Cogan (1980) subdivisent les levains mixtes en quatre groupes selon leur composition en bactéries d'arôme :

a) les levains du type B (B comme Betacoccus) contiennent des Leuconostocs producteurs d'arôme tels que $L$. cremoris, $L$. dextranicum et/ou $L$. lactis ;

b) les levains du type D contiennent $S$. lactis subsp. diacetylactis comme producteur d'arôme ;

c) les levains du type BD contiennent à la fois des Leuconostocs et $S$. lactis subsp. diacetylactis comme producteurs d'arôme ; ques.

d) les levains du type $\mathrm{N}$ ou $\mathrm{O}$ ne contiennent pas de bactéries aromati-

Les principales fonctions demandées aux levains lactiques sont d'après StadHouders (1974): la production d'acide, la protéolyse, la lipolyse, la production de gaz et d'arôme et l'inhibition des bactéries indésirables (pathogènes entre autres).

En ce qui concerne la production d'acide, à part $L$. lactis qui est capable d'acidifier le lait, les autres espèces de Leuconostoc n'acidifient le lait que très lentement (SANDINE et al., 1962) ou en présence d'extrait de levure (GARvie, 1960). C'est la raison principale pour laquelle les Leuconostocs sont toujours 
utilisés en levains mixtes avec des bactéries lactiques acidifiantes (streptocoques du groupe N). Si les Leuconostocs interviennent peu quantitativement dans la production d'acide des levains lactiques, ils jouent un rôle du point de vue qualitatif en produisant de l'acide lactique $\mathrm{D}(-)$ ainsi que de l'acide acétique.

\section{Utilisation des Leuconostocs comme levains d'arôme}

La production de diacétyle et d'acétoïne est sans doute le caractère le plus utilisé des Leuconostocs. Les cultures pures de Leuconostocs et de S. lactis subsp. diacetylactis se comportent d'une façon entièrement différente eu égard à la production de diacétyle et d'acétoïne (Cogan, 1975). Dans du lait ou dans $\mathrm{du}$ bouillon contenant du citrate, $S$. lactis subsp. diacetylactis produit du diacétyle, de l'acétoïne et consomme le citrate dès que la croissance commence.

Les cultures pures de Leuconostocs utilisent le citrate très rapidement, par contre elles ne produisent du diacétyle et de l'acétoïne que tardivement, lorsque le milieu est devenu suffisamment acide.

WaLsh et Cogan (1973) ont mesuré les quantités de citrate utilisé et les productions dans le lait à $21^{\circ} \mathrm{C}$ d'acétoïne, de diacétyle, d'acétaldéhyde et d'acide lactique par différents levains mixtes (type D, B et BD). Ils ont montré que les cultures contenant $S$. diacetylactis (BD et D) utilisaient le citrate plus rapidement et produisaient plus de diacétyle, d'acétoïne et d'acétaldéhyde que les levains de type B (Leuconostocs seuls). Comme l'avaient montré DE MAN et Galesloot (1962) dans les cultures de levains mixtes, l'addition de manganèse $\left(\mathrm{Mn}^{++}\right)$stimule la croissance des Leuconostocs, mais non celle des streptocoques et influe donc sur la vitesse de fermentation des citrates dans les levains contenant $L$. cremoris.

La croissance de $L$. cremoris est nettement plus lente dans les laits de printemps que dans les laits d'automne mais elle peut être stimulée par l'addition de petites quantités (de l'ordre de $10 \mu \mathrm{g} / \mathrm{kg}$ ) de manganèse au lait (Stadhouders, 1974 ; Jensen et Overby, 1970). L'addition de manganèse au lait peut ainsi éliminer les conséquences de variations saisonnières sur les levains mixtes dans la composition desquels entrent les Leuconostocs.

La production de diacétyle par les levains mixtes est optimum à $21^{\circ} \mathrm{C}$ (PAck et al., 1968). Des températures d'incubation plus élevées provoquent une destruction plus rapide du diacétyle (LACRAmpe et Weber, 1973). Pour ces auteurs, la fabrication de levains et de caillés maigres à l'aide de souches mixtes de bactéries acidifiantes et aromatiques concentrées congelées conduit à l'obtention de produits d'excellente qualité qui, grâce à un apport massif de L. citrovorum ont une teneur en diacétyle supérieure à celle des fabrications traditionnelles.

Pour Galesloot et Hassing (1961) les différences des propriétés entre Str. diacetylactis et $L$. cremoris sont responsables des différences constatées entre les levains du type B et les levains du type D.

- Str. diacetylactis croît mieux dans le lait que L. cremoris, même si l'on tient compte de la production par les streptocoques lactiques de substances qui stimulent les Leuconostocs. 
- L. cremoris ne se développe pas de la même façon dans les laits à différentes saisons. Str. diacetylactis n'est pas sensible à ce phénomène.

- Str. diacetylactis a une température optimale supérieure à celle de Str. cremoris. L. cremoris a une température optimale inférieure.

- L. cremoris réduit l'acétoïne et le diacétyle en butylène-glycol, pas Str. diacetylactis.

- L. cremoris a besoin de plus de calcium que Str. cremoris et Str. diacetylactis.

\section{Utilisation des Leuconostocs pour améliorer la structure des fromages}

Les Leuconostocs sont utilisés pour améliorer l'ouverture des fromages. Pour Stadhouders (1986), lorsque I'on recherche des ouvertures dans le fromage l'emploi de levains BD est préférable car les levains BD montrent dans le fromage une fermentation de l'acide citrique plus active et par conséquent produisent plus de $\mathrm{CO}_{2}$ donc plus d'yeux que les levains $\mathrm{B}$ (ouverture normale des fromages d'Edam et de Gouda). Dans ce cas on utilise des souches de $L$. cremoris qui sont des souches faibles productrices de gaz dans le lait. SANDINE et al. (1962) en utilisant les méthodes manométriques de Umbreit et al. (1957) ont montré que les Leuconostocs utilisés comme levains produisaient moins de $50 \mu \mathrm{l}$ de $\mathrm{CO}_{2}$ sur lait pendant 4 heures à $30^{\circ} \mathrm{C}$.

En utilisant une méthode similaire UmBreIt et al. (1964), Devoyod et al. (1974a) ont sélectionné sur lait supplémenté (5\% glucose) des souches de L. mesenteroides fortes productrices de $\mathrm{gaz}\left(>400 \mu \mathrm{l}\right.$ de $\mathrm{CO}_{2}$ pendant 30 minutes à $30^{\circ} \mathrm{C}$ pour une population d'environ $1 \times 10^{9}$ cellules revivifiables). L'utilisation de telles souches sous forme de suspensions concentrées congelées (ACCOLAS et AUClair, 1967) provoque une ouverture régulière du caillé des fromages à pâte persillée et permet un développement correct de Pencillium roqueforti. Dans le cas du fromage de Roquefort, l'ensemencement était de $4 \mathrm{~g}$ de suspension, contenant $1,5 \times 10^{11}$ bactéries par gramme, pour 100 litres de lait (Devoyod et al., 1974b).

\section{Utilisation des Leuconostocs pour éliminer certains défauts de goût}

L'acétaldéhyde est un produit du métabolisme des streptocoques lactiques mésophiles. Les souches de Str. diacetylactis en produisent plus que Str. lactis ou Str. cremoris. Une petite quantité d'acétaldéhyde est reconnue comme participant à l'obtention d'un bon arôme ; par contre une surproduction de ce composé par rapport au diacétyle provoque un défaut dit de «vert» ou d'«âcre » (Lindsay et al., 1965). Ce défaut peut être enrayé par l'emploi de souches de levains qui métabolisent l'acétaldéhyde. Parmi les microorganismes qui rentrent dans la composition des levains $L$. citrovorum s'est trouvé être le plus actif (KeENAN et LindSAY, 1966 ; LAwrence et al., 1976). Selon KeEnAN et al. (1966) il est possible d'éliminer le défaut de « vert » d'une culture de bactéries lactiques en utilisant les Leuconostocs ; mais pour cela il est nécessaire d'en ajouter une grande quantité.

L'addition de petites quantités d'une culture de $L$. cremoris à une culture de bactéries lactiques n'a que peu d'effet sur la teneur en acétaldéhyde de la culture maturée parce que la population de Leuconostocs est très faible par 
rapport à celle de bactéries lactiques. Les quelques cellules de Leuconostocs sont vraisemblablement rapidement surpassées par les streptocoques qui métabolisent activement, et elles doivent s'adapter pour se développer et croître dans de nouvelles conditions. LODE et Tufro (1973) ont montré que la proportion de Str. diacetylactis et de $L$. citrovorum augmentait lorsque la température d'incubation des cultures mixtes s'élevait de 18 à $24^{\circ} \mathrm{C}$. Toutefois, dans les levains mixtes, ne contenant pas $S$. diacetylactis, la proportion de L. citrovorum était peu affectée par la température d'incubation. De plus, les streptocoques lactiques sont capables de métaboliser des substances antibiotiques qui inhibent ou restreignent la croissance et la multiplication de $L$. cremoris (Kooy et Pette, 1952; Marth, 1962; KozAK et al., 1978).

\section{Autres utilisations}

Les dextranes produits par $L$. mesenteroides associées à l'épichlorhydrine ont été utilisés dans les procédés de filtration sur gel de concentration ou de récupération de protéines à partir de lactosérum de fromagerie (LAWFORD et al., 1979).

L. mesenteroides a été associé à Xanthomonas campestris pour produire des bouillons visqueux à partir de lactosérum supplémenté en saccharose (Schwartz et Bodie, 1984).

\section{Perspectives}

Les Leuconostocs sont susceptibles de jouer de nombreux rôles positifs en technologie laitière, beurrière ou fromagère. Mais une certaine méconnaissance de leur physiologie a pour conséquence, très souvent, une mauvaise utilisation de ces microorganismes. On peut qualifier les Leuconostocs de microorganismes « associatifs stricts » quel que soit le rôle qui leur est demandé, il s'agit d'un rôle complémentaire. Des interactions entre les Leuconostocs et les levains lactiques vont dépendre le rendement, la réussite de l'utilisation des Leuconostocs. KeEnan et al. (1966) ont très bien montré l'importance des interactions entre bactéries lactiques et Leuconostocs et la nécessité de maintenir un certain rapport entre ces microorganismes pour que les Leuconostocs puissent exprimer pleinement tout leur métabolisme. Dans ce cas précis il s'agissait de la transformation de l'acétaldéhyde en éthanol.

L'utilisation des Leuconostocs sous forme de suspensions concentrées congelées permet en grande partie de pallier l'inconvénient de cultures mixtes ou très souvent les Leuconostocs se trouvent défavorisés. Cette forme d'utilisation est d'autant plus intéressante que les souches de Leuconostocs gardent sous cette forme leur activité physiologique pendant plusieurs mois, qu'il s'agisse de la propriété de produire du gaz (Devoyod et al., 1974b) ou de produire du diacétyle (OBERMAn et al., 1986). Le résultat de l'action des Leuconostocs ne dépend pas seulement des bactéries lactiques des levains ou de la flore naturelle des laits mais également de la flore non lactique. Certains microorganismes comme les streptocoques du groupe D (Devoyod et DesmazEAUd, 1970) ou les levures (Devoyod et Muller, 1969) ont une action stimulante vis-à-vis des Leuconostocs, d'autres comme les microcoques caséolytiques peuvent avoir une action inhibitrice (Devoyod et al., 1972). L'utilisation 
des Leuconostocs sous forme de suspensions concentrées congelées permet d'éviter en partie ces interactions.

La propriété des Leuconostocs de produire des substances inhibitrices n'est pas présentement volontairement utilisée. Il devrait y avoir là une perspective d'autant plus intéressante que les microorganismes les plus inhibés appartiennent au genre Pseudomonas, microorganismes qui posent bien des problèmes actuellement en technologie laitière et fromagère par suite de leur prolifération dans les laits refroidis, par exemple.

\section{Conclusion}

Parmi les bactéries lactiques, les Leuconostocs, à part peut-être L. cremoris, sont certainement les microorganismes les moins bien connus bien que possédant des qualités complémentaires de celles des autres bactéries lactiques; leur utilisation dans de nombreux secteurs de la technologie laitière n'est encore que très fragmentaire, pour ne pas dire nulle.

Une meilleure connaissance de leur physiologie, des phénomènes d'association avec les streptocoques lactiques et (ou) les lactobacilles mésophiles, devrait leur permettre d'atteindre, au niveau des levains industriels, l'importance qu'ils ont dans la flore lactique des produits laitiers fabriqués à partir de lait cru.

Reçu le 9 décembre 1986

Accepté pour publication le 15 janvier 1988

\section{Remerciements}

Les auteurs remercient $M$. DESMAZEAUD pour les conseils donnés au cours de la rédaction du manuscrit.

\section{Références bibliographiques}

Abd-el-Malek Y., Gibson T., 1948. Studies in the bacteriology of milk. I. The streptococcus of milk. J. Dairy Res., 15, 233-248.

Accolas J.P., Auclair J., 1967. Conservation à l'état congelé de suspensions de bactéries lactiques concentrées sous faible volume. I. Bactéries lactiques mésophiles. Lait, 47, 253-260.

ArIAs A., 1985. Caractérisation biochimique et profil plasmidique de souches de leuconostoc du lait. Mémoire DEA Sciences des Aliments, ENSBANA, Université de Dijon.

BABel F.J., 1977. Antibiosis by lactic culture bacteria. J. Dairy Sci., 60, 815-821.

BeIJerincK M.W., 1912. Die durch Bakterien aus Rohrzucker erzeugten schleimigen Wandstoffe. Folia Microbiol., 377-408.

Bellon-Fontaine M.N., Cerf O., 1986. Energie d'adhésion de bactéries à des surfaces inertes. Premiers résultats avec Leuconostoc mesenteroides. Sci. Aliments, 6, $\mathrm{n}^{\circ}$ hors série VI, 183-187. 
BoCquien C.Y., 1987. Communication personnelle.

Branen A.L., Keenan T.W., 1971. Diacetyl and acetoin production by Lactobacillus casei. Appl. Microbiol., 22, 517-521.

Branen A.L., Go H.C., Genske R.P., 1975. Purification and properties of antimicrobial substances produced by Streptococcus diacetilactis and Leuconostoc citrovorum. J. Food Sci., 40, 446-450.

BRoOKer B.E., 1976. Surface coat transformation and capsule formation by Leuconostoc mesenteroides NCDO 523 in the presence of sucrose. Arch. Microbiol., 111, 99-104.

BROOKER B.E., 1977. Ultrastructural surface changes associated with dextran synthesis by Leuconostoc mesenteroides. J. Bacteriol., 131, 288-292.

Chen K.H., McFeeters R.F., Fleming H.P., 1983. Fermentation characteristics of heterolactic acid bacteria in green bean juice. J. Food Sci., 48, 962-966.

Сномакоv K.H., 1975. Species composition of catalase negative streptococci in raw and pasteurized cows'milk for white pickled cheese manufacture. Zhivotnov'dni Nauki, 12, 119-126.

Christopher F.M., Vanderzant C., Carpentier Z.L., Smith G.C., 1979. Microbiology of pork packaged in various gas atmospheres. J. Food Prot., 42, 323-327.

McCleskey C.S., Faville L.W., Barnett R.O., 1947. Characteristics of Leuconostoc mesenteroides from cane juice. J. Bacteriol., 54, 697-705.

Cogan T.M., 1975. Citrate utilization in milk by Leuconostoc cremoris and Streptococcus diacetilactis. J. Dairy Res., 42, 139-146.

Cogan T.M., 1980. Les levains lactiques mésophiles. Une revue. Lait, 60, 397-425.

CoGAN T.M., 1981. Constitutive nature of the enzymes of citrate metabolism in Sreptococcus lactis ssp diacetylactis. J. Dairy Res., 48, 489-495.

Cogan T.M., O’Dowd M., Mellerick D., 1981. Effects of $\mathrm{pH}$ and sugar on acetoin production from citrate by Leuconostoc lactis. Appl. Environ. Microbiol., 41, 1-8.

Cogan T.M., Fitzgerald R.J., Doonan S., 1984. Acetolactate synthase of Leuconostoc lactis and its regulation of acetoin production. J. Dairy Res., 51, 597-604.

Collins E.B., Speckman R.A., 1974. Influence of acetaldehyde on growth and acetoin production by Leuconostoc citrovorum. J. Dairy Sci., 57, 1428-1431.

CотE G.L., Rовут J.F., 1983. The formation of $\alpha$-D- $(1 \rightarrow 3)$ branch linkages by an exocellular glucansucrase from Leuconostoc mesenteroides NRRL B-742. Carbohydr. Res., 119, 141-156.

Daly C., Sandine W.E., Elliker P.R., 1972. Interactions of food starter cultures and food-borne pathogens * Streplococcus diacetylactis versus food pathogens. J. Milk Food Technol., 35, 349357.

Demeter K.J., 1956. Die am häufigsten in der Butter vorkommenden Arten von Mikroorganismen, nebst wichtigeren, sporadish auftretenden. In: Mikrobiologie der Butter. Stuttgart, E. Uimer. 38-51.

Devoyod J.J., Desmazeaud M., 1970. Les associations microbiennes dans le fromage de Roquefort. I Action des entérocoques vis-à-vis des streptocoques lactiques et des leuconostocs. Lait, 50, 374-390.

Devoyod J.J., Desmazeaud M., Assenat L., Auclair J., 1972. Les associations microbiennes dans le fromage de Roquefort. IV. Action inhibitrice des microcoques caséolytiques sur l'ouverture du caillé. Lait, 52, 297-310.

Devoyod J.J., Muller M., 1969. La flore microbienne du fromage de Roquefort. III. Les streptocoques lactiques et les leuconostoc. Influence de différents microorganismes de contamination. Lait, 49, 369-399.

Devoyod J.J., Melcion D., Auclair J., 1974a. Standards of selection of leuconostoc strains used in the making of Roquefort cheese. 19 $9^{\text {th }}$ Int. Dairy Congr., New Delhi, Vol. 1E, 419.

Devoyod J.J., LabBe M., Auclair J., 1974b. Concentrated frozen suspensions of leuconostoc for Roquefort cheesemaking. 19 $9^{\text {th }}$ Int. Dairy Congr., New Delhi, Vol. 1E, 421.

Devoyod J.J., Millet L., Rousseau M., 1987. Rôle de la vaisselle laitière dans les fabrications traditionnelles : cas des fromages à pâte pressée demi-dure. Colloque "Histoire et géographie des fromages ", Caen, 18-20/09/85, Centre Publications Université de Caen.

Didienne R., Devoyod J.J., 1978. Late blowing in cheeses made from uncooked curd. $20^{\text {th }}$ Int. Dairy Congr., Paris, Vol. 1E, 760. 
Didienne R., Millet L., Devoyod J.J., Valladier J., 1978. Use of specific starters in cheesemaking at the Laguiole dairy. $20^{\text {th }}$ Int. Dairy Congr., Paris, Vol. 1E, 586.

McDonald R.F., McFeeters R.F,, Daeschel. M.A., Fleming H.P., 1987. A differential medium for the enumeration of homofermentative and heterofermentative lactic acid bacteria. Appl. Environ. Microbiol., 53, 1382-1384.

Dorner W., Demont P., Chavannes D., 1952. Microbiologie de la crème et du beurre. In : Microbiologie laitière, Lausanne, Payot.

Drinan D.F., Tobin S., Cogan T.M., 1976. Citric acid metabolism in hetero-and homofermentative lactic acid bacteria. Appl. Environ. Microbiol., 3I, 481-486.

El-Gendy S.M., AbD-El-Galil H., Shahin Y., Hegazi F.Z., 1983. Characteristics of salt-tolerant lactic acid bacteria in particular lactobacilli, leuconostoc and pediococci isolated from salted raw milk. J. Food Prot., 46, 429-433.

Evans A., 1918. A study of the streptococci concerned in cheese ripening. J. Agric. Res., 13, 235252.

Fatichenti F., Delana P., Farris G.A., Soggia G., 1979. Etudes microbiologiques sur le lait et le fromage de chèvre en Sardaigne. Lait, 59, 387-400.

FENTON M.P., 1987. An investigation into the sources of lactic acid bacteria in grass silage. J. Appl. Bacteriol., 62, 181-188.

Galesloot T., 1950. An early gas defect in cheese caused by Betacoccus (Leuconostoc) species with some remarks about the nomenclature of Betacoccus (Leuconostoc) species. Neth. Milk Dairy J., 4, 274-287.

GalesLoot T.E., 1962. The bacteriology and biochemistry of starters and ripened cream. $16^{\text {th }}$ Int. Dairy Congr., Copenhagen, D, 143-161.

Galesloot T.E., Hassing F., 1961. Enkele verschillen in gedrag tussen zuursels met als aromabacterie Streptococcus diacetilactis of Betacoccus cremoris. Neth. Milk Dairy J., 15, 225-247.

Garvie E.I., 1960. The genus Leuconostoc and its nomenclature. J. Dairy Res., 27, 283-292.

Garvie E.I., 1967a. Leuconostoc oenos sp. nov. J. Gen. Microbiol., 48, 85-94.

Garvie E.I., 1967b. The growth factor and amino acid requirements of species of the genus Leuconostoc including Leuconostoc paramesenteroides (sp. nov) and Leuconostoc oenos. J. Gen. Microbiol, 48, 439-447.

Garvie E.I., 1974. Gram-positive cocci. Genus II Leuconostoc. In : Bergey'sManual, 8th edit., the Williams and Wilkins Co., Baltimore, 510-513.

Garvie E.I., 1976. Hybridization between the deoxyribonucleic acids of some strains of heterofermentative lactic acid bacteria. Int. J. Syst. Bacteriol., 26, 116-122.

Garvie E.I., 1979. Proposal of neotype strains for Leuconostoc mesenteroides (Tsenkovskii) van Tieghem, Leuconostoc dextranicum (Beijerinck) Hucker and Pederson, and Leuconostoc cremoris (Knudsen and Sørensen) Garvie, Int. J. Syst. Bacteriol,, 29, 149-151.

Garvie E.I., 1983. Leuconostoc mesenteroides subsp cremoris (Knudsen and Sørensen) comb, nov. and Leuconostoc mesenteroides subsp dextranicum (Beijerinck) comb. nov. Int. J. Syst. Bacteriol., 33, 118-119.

GARviE E.I., 1984. Separation of species of the genus Leuconostoc and differenciation of the Leuconostocs from other lactic acid bacteria. Methods Microbiol., 16, 147-178.

Garvie E.I., 1986. Gram positive cocci - Genus Leuconostoc. In : Bergeys'Manual, 9th edit., the Williams and Wilkins Co., Baltimore, 1071-1075.

Genske R.P., Branen A.L., 1973. Properties of antimicrobial substances with $S$. diacetilactis and L. citrovorum. Modern Dairy, 52, (7/8), 12-14.

De Giori G.S., De Valdez G.F., De Ruiz Holgado A.P., Oliver O+, 1983, Microflora of Tafi cheese : changes during manufacture and maturation. J. Food Prot., 46, 518-521.

Goldberg M., Fessenden J.M., Racker E., 1966. Phosphoketolase. Method Enzymol., 9, 515520 .

Grazia L., Suzzi G., 1984. A survey of lactic acid bacteria in Italian silage, J. Appl. Bacteriol., $56,373-379$.

HAINES W.C., 1972. Growth and production of enterotoxin by Staphylococcus aureus grown in association with selected lactic acid bacteria. Diss. Abstr. Int., B33, 2171-2172. 
Hammer B.W., 1920. Volatile acid production of S. lactis and the organisms associated with it in starters. Iowa Agric. Exp. Stn Res. Bull. (63), 1-96.

Harvey R.J., Collins E.B., 1961. Role of citritase in acetoin formation by Streptococcus diacetilactis and Leuconostoc citrovorum. J. Bacteriol., 82, 954-959.

Harvey R.J., Collins E.B., 1962. Citrate transport system of Streptococcus diacetilactis. J. Bacteriol., 83, 1005-1009.

Harvey R.J., Collins E.B., 1963. Roles of citrate and acetoin in the metabolism of Streptococcus diacetilactis. J. Bacteriol., 86, 1301-1307.

Hegazi F.Z., Abo-Elnaga I.G, 1980. Degradation of organic acids by dairy acid bacteria. Zentralbl. Bakteriol. II Abt., 135, 212-222.

Holzapfel W.H., Kriel J.B, 1973. The composition and properties of commercial cheese starters. S. Afr. J. Dairy Technol., 5, II-14 (In D.S.A. 1973, 3617).

Hontebeyrie M., Gasser F., 1975. Comparative immunological relationships of two distinct sets of isofunctional dehydrogenases in the genus Leuconostoc. Int. J. Syst. Bacteriol., 25, 1-6.

Hontebeyrie M., Gasser F., 1977. Deoxyribonucleic acid homologies in the genus Leuconostoc. Int. J. Syst. Bacteriol., 27, 9-14.

Hucker G.J., 1928. Studies on the Coccaceae. XIV. Certain biochemical reactions produced by the streptococci. N.Y. State Agric: Exp. Sin Techn. Bull. (143), 1-64.

Hucker G.J., Pederson C.S., 1931. A study of the physiology and classification of the genus Leuconostoc. Zentralbl. Bakteriol., II Abt. 85, 65-114.

Ito S., Kobayashi T, Ohta Y., Akiłama Y., 1983. Inhibition of glucose catabolism by aeration in Leuconostoc mesenteroides. J. Ferment. Technol, 61, 353-358.

JENSEN J.S., Overby A.J., 1970, The bacteriological composition of starter : the influence of solids-non fat content in milk. $18^{\text {th }}$ Int. Dairy Congr., Sydney, Vol. 1 E, 129.

JUFFS H.S., BABEL F.J., 1975. Inhibition of psychrotrophic bacteria by lactic cultures in milk stored at low temperature. J. Dairy Sci, 58, 1612-1619.

KeEnan T.W., Lindsay R.C., 1966. Removal of green flavor from ripened butter cultures. J. Dairy Sci., 49, 1563-1565.

KeEnan T.W., Lindsay R.C., Day E.A., 1966. Acetaldehyde utilization by leuconostocs. Appl. Microbiol., 14, 802-806.

Kekessy Y.D.A., Piguet J.D., 1970. New method for detecting bacteriocin production. Appl. Microbiol., 20, 282-283.

Kempler G.M., McKay L.L., 1980. Improved medium for detection of citrate-fermenting Streptococcus lactis ssp diacetylactis. Appl. Environ. Microbiol., 39, 926-927.

Kempler G.M., McKay L.L., 1981. Biochemistry and genetics of citrate utilization in Streptococcus lactis ssp diacetylactis. J. Dairy Sci, 64, 1527-1539.

Kobayascht M., Matsuda K., 1974. The dextransucrase isoenzymes of Leuconostoc mesenteroides. Biochim. Biophys. Acta, 370, 441-449.

Kobayaschi M., Matsuda K., 1986. Electrophoretic analysis of the multiple forms of dextransucrase from Leuconostoc mesenteroides. J. Biochem., 100, 615-621.

Kooy J.S., PetTE J.W., 1952. Remming van de groei van lactaatvergistende boterzuurbakteriën door antibiotica van melkzuurstreptococcen. Neth. Milk Dairy J., 6, 302-316.

Kozak W., Bardowski J., Dobranski W.T., 1978. Lactostrepcins-acid bacteriocins produced by lactic streptococci. J. Dairy Res., 45, 247-257.

Kroulik J.T., Burkey L.A., Wiseman H.G., 1955. The microbial populations of the green plant and of the cut forage prior to ensiling. J. Dairy Sci., 38, 256-262.

Krusch U., 1984. Mikrobiologische charakterisierung von Kefir: Bakteriologie, Keimzahlen, Hauptgärprodukte. Dtsch. Molk. Ztg., 105, 1332, 1334-1335.

Lacrampe J.L., Weber F., 1973. Teneur en diacétyle de levains et caillés maigres fabriqués à partir de bactéries lactiques concentrées, congelées, conservées sous azote liquide. Lait, 53, 491-519.

LAKEW B., 1982. Energie de surface et adhésion de Leuconostoc mesenteroides NCDO 523 à des surfaces inertes. Thèse de $3^{\mathrm{c}}$ cycle, Université Paris VI. 
Langston C.W., Bouma C., 1960. A study of the microorganisms from grass silage. I. The cocci. Appl. Microbiol., 8, 212-222.

Langston C.W., Bouma C., Conner R.M., 1962. Chemical and bacteriological changes in grass silage during the early stages of fermentation. II. Bacteriological changes. J. Dairy Sci., 45, 618-624.

Lawford G.R., Kligerman A., Williams T., 1979. Dextran biosynthesis and dextransucrase production by continuous culture of Leuconostoc mesenteroides. Biotechnol. Bioeng,, 21, 11211131.

Lawrence R.C., Thomas T.D., Terzagh B.E., 1976. Reviews of the progress of Dairy Science: cheese starters. J. Dairy Res., 43, 141-193.

LeEs G.J., Jago G.R., 1976. Acetaldehyde : an intermediate in the formation of ethanol from glucose by lactic acid bacteria. $J_{+}$Dairy Res., 43, 63-73.

Lindsay R.C., Day E.A., SANDine W.E., 1965. Green flavor defect in lactic starter cultures, $J$. Dairy Sci, $48,863-869$.

LODE A., Turto G.N., 1973. Effect of incubation time and temperature and substrate composition on bacterial content and acid production of various starters. Meieriposten, 62, 687-697; 723 732 ; 746-759 ; $768-774$ (Dairy Sci. Abstr. (1974) 36, 1123).

London J., Chase N.M., 1976. Aldolases of the lactic acid bacteria. Arch. Microbiol., 110, 121128.

Lonvaud-Funel A., Strasser de SaAd A.M., 1982. Purification and properties of a malolactic enzyme from a strain of Leuconostoc mesenteroides isolated from grapes. Appl. Environ. Microbiol., 43, 357-361.

Lucey C.A., Condon S., 1986. Active role of oxygen and NADH oxydase in growth and energy metabolism of Leuconostoc. J. Gen. Microbiol., 132, 1789-1796.

Mabitt L.A., Zielinska M., 1956. The use of a selective medium for the enumeration of lactobacilli in cheddar cheese. $J_{+}$Appl. Bacteriol, 19, 95-101.

De Man J.C., Rogosa M., Sharpe M.E., 1960. A medium for the cultivation of lactobacilli, J. Appl. Bacteriol., 23, 130-135.

De Man J.C., Galesloot T.E., 1962. De invloed van aen toevoeging van mangaan aan de melk op de groei van zuurselbacteriën. Neth. Milk Dairy J., I6, 1-23.

MAREt R., Sozzı T., 1976. Flore lactique de fromageries dalpages suisses. Lait, 56, 304-318.

Marth E.H., 1962. Symposium on lactic starter cultures. III. Certain aspects of starter culture metabolism. J. Dairy Sci., 45, 1271-1281.

Marth E.H., Hussong R.V., 1963. Effect of skimmilks cultured with different strains of Leuconostoc citrovorum on growth of some bacteria and yeasts. J. Dairy Sci., 46, 1033-1037.

Mather D.W., Babel. F.J., 1959. Inhibition of certain types of bacterial spoilage in creamed cottage cheese by the use of a creaming mixture prepared with Streptococcus citrovoris. J. Dairy Sci., 42, 1917-1926.

Mayeux J., Sandine W., Elliker P., 1962. A selective medium for detecting Leuconostoc organisms in mixed strain starter cultures. J. Dairy Sci., 45, 655.

Mellerick D., Cogan T.M., 1981. Induction of some enzymes of citrate metabolism in Leuconostoc lactis and other heterofermentative lactic acid bacteria. J. Dairy Res., 48, 497-502.

Millet L., Melcion D., Devoyod J.J., 1974. La flore microbienne du fromage de Cantal fabriqué à partir de lait cru. I. Technique d'études et résultats préliminaires. Lait, 54, 397-407.

Millet L., Didienne R., Devoyod J.J., 1978. The microbial flora of " Cantal " cheese made with raw and heat treated cows'milk. $19^{\text {th }}$ Int. Dairy Congr., Paris, Vol. 1 E. 758-759.

Millet L., Rousseau M., Devoyod J.J., 1984. Implantation des levures dans la vaisselle laitière. $6^{\mathrm{c}}$ Symposium International sur les Levures, Montpellier, 3.9.07: X 5.0.

Minor T.E., Marth E.H., 1970. Growth of Staphylococcus aureus in acidified pasteurized milk. J. Milk Food Technol, 33, 516-520.

DE Moss R.D., 1954. A triphosphopyridine nucleotide-dependent alcohol dehydrogenase from Leuconostoc mesenteroides. J. Bacteriol., 68, 252-257.

DE Moss R.D., Bard R.C., Gunsalus I.C., 1951. The mechanism of the heterolactic fermentation. A new route of ethanol formation. J. Bacteriol., 62, 499-511. 
Mostert J.F., Husmann R.A., 1975. The bacteriological composition of some commercial starters used for Gouda cheese manufacturing. S. Afr. J. Dairy Technol., 7, 179-181 (In D.S.A., 1976-2397).

Nunez M., 1978. Microflora of Cabrales cheese : changes during maturation. J. Dairy Res., 45, 501-508.

Nunez M., Medina M., 1979. La flore lactique du fromage bleu de Cabrales. Lait, 59, 497-513.

Nunez J.A., Chavarri F.J., Nunez M., 1984. Psychrotrophic bacterial flora of raw ewes'milk, with particular reference to Gram-negative rods. J. Appl. Bacteriol., 57, 23-29.

Oberman H., Libudzisz Z., Piatkiewicz A., 1986. Physiological activity of deep-frozen concentrates of Leuconostoc strains. Nahrung, 30, 147-154.

Olsson G., 1981. Kefir - ett naturens under. Livsmedelsteknik, 23, 428-429 - (In D.S.A. 1984 3825).

Orberg P.R., SANDine W.E., 1984. Common occurence of plasmid DNA and vancomycin resistance in Leuconostoc spp. Appl. Environ. Microbiol, 48, 1129-1133.

Ordonez J.A., Barneto R., Marmol M.P., 1978. Identificacion de la flora que participa en la maduracion del queso manchego. An. Bromatol., 30, 361-373.

Ordonez J.A., Masso J.A., Marmol M.P., Ramos M., 1960. Contribution à l'étude du fromage « Roncal ». Lait, 60, 283-294.

Orla-Jensen S., 1919. The lactic acid bacteria. Mem. Acad. Roy. Sci. Let., Copenhagen, Sect. Sci., 5, 81-196.

Orla-Jensen S., Orla-Jensen A.D., Spur B., 1926. Les bactéries d'arôme du beurre. Lait,. 6 , 161-169.

O'Sullivan T., Daly C., 1982. Plasmid in Leuconostoc species. J. Food Sci. Technol., 6, 206.

Ottogalli G., Galli A., Rondinini G., Volonterio G., 1975. Microbiology of Pannerone cheese. Ind. Latte, 11, 7-17.

Overcast W.W., Albrecht T.W., 1952. Gas production in cheddar cheese caused by Leuconostoc citrovorum. J. Dairy Sci., 35, 554-558.

Pack M.Y., Vedamuthu E.R., Sandine W.E., Elliker P.R., Leesment H., 1969. Effect of temperature on growth and diacetyl production by aroma bacteria in single-and mixed-strain lactic cultures. J. Dairy Sci., 51, 339-344.

PARK H.S., MARTH E.H., 1972. Behavior of Salmonella typhimurium in skim milk during fermentation by lactic acid bacteria. J. Milk Food Technol., 35, 482-487.

Pederson C.S., Albury M.N., 1955. Variation among the heterofermentative lactic acid bacteria. J. Bacteriol., 70, 702-708.

Perry K.D., Sharpe M.E., 1960. Lactobacilli in raw milk and in Cheddar cheese. J. Dairy Res., $27,267-275$.

Pidoux M., 1985. Le grain de Kéfir et sa formation. Etudes biochimiques et microbiologiques. Thèse Doct. $3^{c}$ cycle, Univ., Nantes.

Pinheiro A.J.R., Liska B.J., Parmelee C.E., 1968. Properties of substances inhibitory to Pseudomonas fragi produced by Streptococcus citrovorus and Streptococcus diacetilactis. J. Dairy Sci., $51,183-187$.

Radler F., Brohl L., 1984. The metabolism of several carboxylic acids by lactic acid bacteria. Z. Lebensm. Unters. Forsch., 179, 228-231.

Ramos M., Barneto R., Ordonez J.A., 1981. Evaluation of a specific starter for Manchego cheese production. Milchwissenschaft, 36, 528-531.

Reddy S.G., Henrickson R.L., Olson H.C., 1970. The influence of lactic cultures on ground beef quality. J. Food Sci., 35, 787-791.

Riemelt I., 1982. Isolation and differentiation of Leuconostoc cremoris. 21st Int. Dairy Congr., Moscow, Vol. 1, book 2, 358-359.

Robrt J.F., WALSETH T.F., 1978. The mechanism of acceptor reactions of Leuconostoc mesenteroides B-512 F dextransucrase. Carbohyd. Res., 61, 433-445.

Rogosa M., Mitchell J.A., Wiseman R.F., 1951. A selective medium for the isolation of oral and faecal lactobacilli. J. Bacteriol., 62, 152-153. 
Ross G.R., 1981. The inhibition of growth of spoilage microorganisms in milk by Streptococcus lactis subsp. diacetylactis, Leuconostoc cremoris and L. dextranicum. Aust. J. Dairy Technol., $36,147-152$.

Sandine W.E., Elliker P.R., Anderson A.W., 1959. Taxonomic study of high carbon dioxideproducing lactic acid streptococci isolated from mixed strain starter cultures. J. Dairy Sci., 42, $799-808$.

Sandine W.E., Elliker P.R., Hays H., 1962. Cultural studies on Streptococcus diacetilactis and other members of the lactic streptococcus group. Can. J. Microbiol., 8, 161-174.

Savell J.W., Hanna M.O., Vanderzant C., Smith G.C., 1981. An incident of predominance of Leuconostoc sp in vacuum-packaged beef strip loins. Sensory and microbial profile of steaks stored in $\mathrm{O}_{2}-\mathrm{CO}_{2}-\mathrm{N}_{2}$ atmospheres. J. Food Prot., 44, 742-745.

Schwartz R.D., Bodie E.A., 1984. Production of viscous dextran-containing whey-sucrose broths by Leuconostoc mesenteroides ATCC 14935. Appl. Environ. Microbiol., 48, 678-679.

Sharpe E.M., Fryer T.F., Smith D.G., 1966. Identification of the lactic acid bacteria. In : Identification methods for microbiologists. Gibbs \& Skinner ed., London, Academic Press, 6579.

SHERwood I,R, 1939. The bacterial flora of New-Zealand Cheddar cheese. J. Dairy Res., 10, 426448.

Sмiтн E.E., 1970. Biosynthetic relation between the soluble and insoluble dextrans produced by Leuconostoc mesenteroides NRLL B. 1299. FEBS Lett., 12, 33-37.

SORRells K.M., SPECK M.L., 1970. Inhibition of Salmonella gallinarum by culture filtrates of Leuconostoc citrovorum. J. Dairy Sci., 53, 239-241.

Sozzi T., Poulin J.M., Maret R., Pousaz R., 1978a. Isolation of a bacteriophage of Leuconostoc mesenteroides from dairy products. J. Appl. Bacteriol., 44, 159-161.

Sozzi T., Poulin J.M., Maret R., 1978b. Etude d'un bactériophage de Leuconostoc mesenteroides isolé de produits laitiers. Schweiz. Milchw. Forschung., 7, 33-40.

Sozzı T., Gnaegı F., D’Amico N., Hose H., 1982. Difficultés de fermentation malolactique du vin dues à des bactériophages de Leuconostoc oenos. Rev. Suisse Vitic. Arboric. Hortic., 14, 1723.

Speckman R.A., Coluns E.B., 1968. Diacetyl biosynthesis in Streptococcus diacetilactis and Leuconostoc citrovorum. J. Bacteriol., 95, 174-180.

Stackebrandt E., Fowler V.J., Woese C.R., 1983. A phylogenetic analysis of lactobacilli, Pediococcus pentosaceus and Leuconostoc mesenteroides. System. Appl. Microbiol., 4, 326-337.

Stadhouders J., 1974. Dairy starter cultures. Milchwissenschaft, 29, 329-337.

Stadhouders J., 1986. The control of cheese starter activity. Neth. Milk Dairy J., 40, 155-173.

Stamer J.R., Stoyla B.O., Dunckel B.A., 1971. Growth rates and fermentation patterns of lactic acid bacteria associated with the sauerkraut fermentation. J. Milk Food Technol, 34, 521-525.

Stirling A.C., Whittenbury R., 1963. Sources of the lactic acid bacteria occuring in silage. J. Appl. Bacteriol., 26, 86-90.

Sutherland I.W., 1982. Biosynthesis of microbial exopolysaccharides. Adv. Microb. Physiol, 23, 79-142.

Swartling Per F., 1951. Biochemical and serological properties of some citric acid fermenting streptococci from milk and dairy products. J. Dairy Res., 18, 256-267.

Van Tieghem P.E.L., 1878. Sur la gomme de sucrerie. Ann. Sci. Nat. Bot., 6, 180-202.

Umbreit W.W., Burris R.H., Stauffer J.F., 1957. Manometric techniques. 3rd ed., Minneapolis, Burgess Publishing Co.

Umbreit W.W., Burris R.H., Stauffer J.F., 1964. Manometric techniques. 4th ed., Minneapolis, Burgess Publishing Co.

Walsh B., Cogan T.M., 1973. Diacetyl, acetoin and acetaldehyde production by mixed-species lactic starter cultures. Appl. Microbiol., 26, 820-825. 